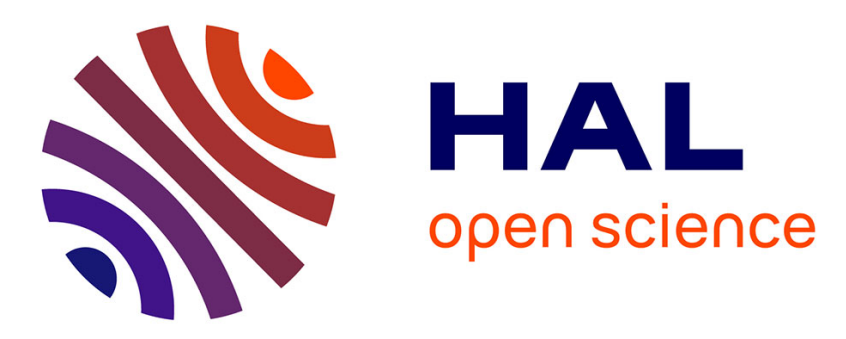

\title{
Sample Preparation Using Molecularly Imprinted Polymers
}

Valérie Pichon, Nathalie N. Delaunay, Audrey Combès

\section{To cite this version:}

Valérie Pichon, Nathalie N. Delaunay, Audrey Combès. Sample Preparation Using Molecularly Imprinted Polymers. Analytical Chemistry, 2019, 92 (1), pp.16-33. 10.1021/acs.analchem.9b04816 . hal-02470623

\section{HAL Id: hal-02470623 \\ https://hal.sorbonne-universite.fr/hal-02470623}

Submitted on 7 Feb 2020

HAL is a multi-disciplinary open access archive for the deposit and dissemination of scientific research documents, whether they are published or not. The documents may come from teaching and research institutions in France or abroad, or from public or private research centers.
L'archive ouverte pluridisciplinaire HAL, est destinée au dépôt et à la diffusion de documents scientifiques de niveau recherche, publiés ou non, émanant des établissements d'enseignement et de recherche français ou étrangers, des laboratoires publics ou privés. 
Anal. Chem. 2020, 92, 1, 16-33

https://doi.org/10.1021/acs.analchem.9b04816

\section{Sample preparation using molecularly imprinted polymers}

Valérie Pichon ${ }^{\mathrm{a}, \mathrm{b} *}$, Nathalie Delaunay ${ }^{\mathrm{a}}$, Audrey Combès ${ }^{\mathrm{a}}$

aLaboratoire des Sciences Analytiques, Bioanalytiques et Miniaturisation - UMR Chimie Biologie Innovation 8231, ESPCI Paris, CNRS, PSL University, 75005 Paris, France

bSorbonne Université, 75005 Paris, France

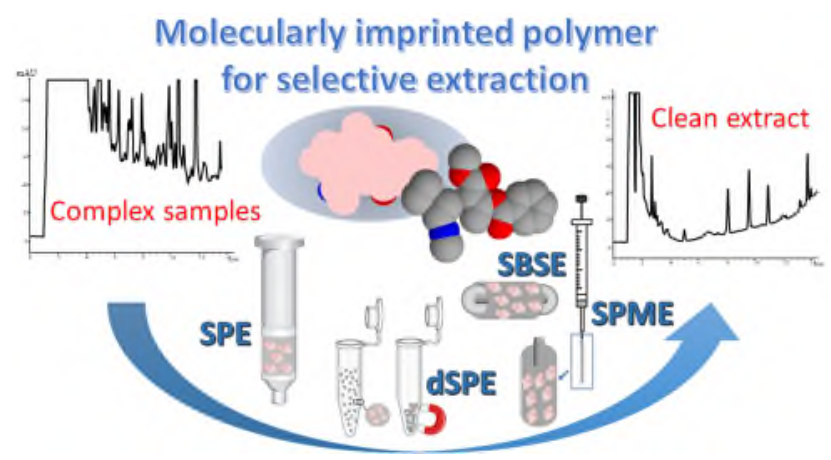

\section{Contents}

Trends in polymerization methods

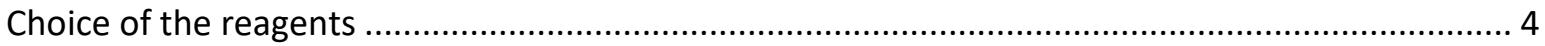

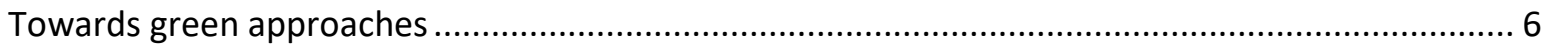

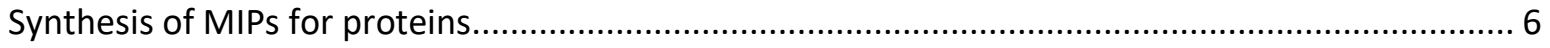

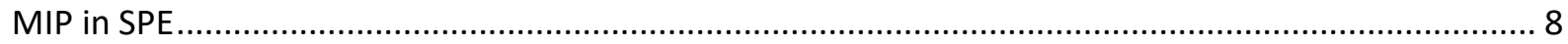

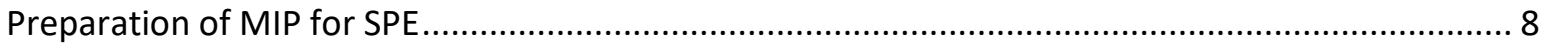

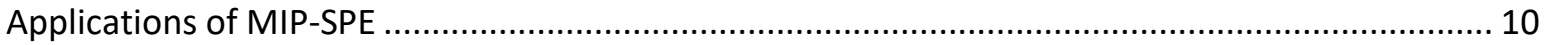

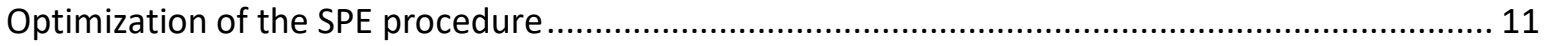

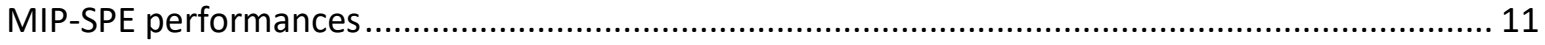

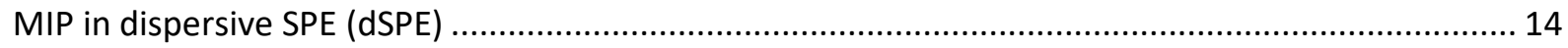

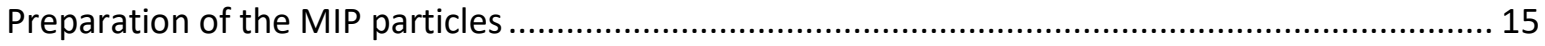

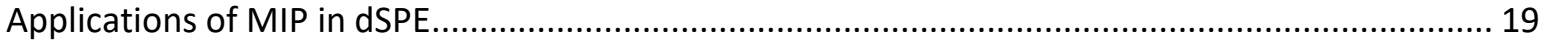

Optimization of the dSPE procedure

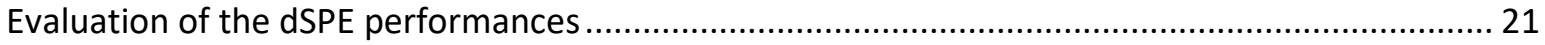

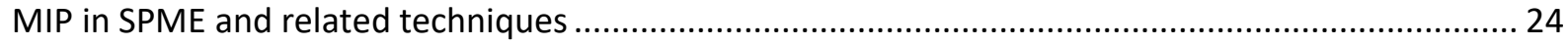

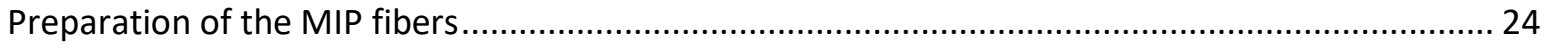

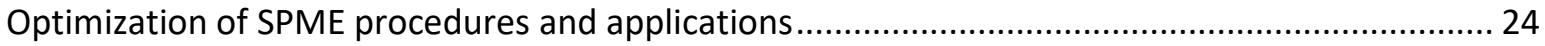

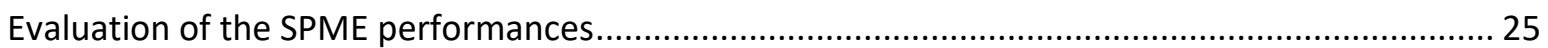

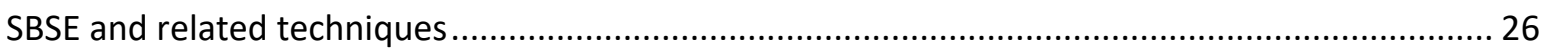

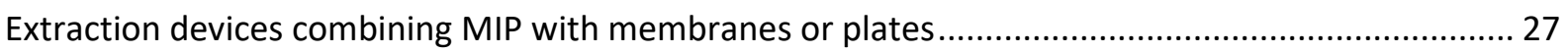

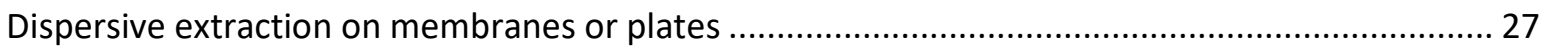


Membrane protected solid-phase extraction

Concentration of target by deposition on membrane/plate surface............................................ 28

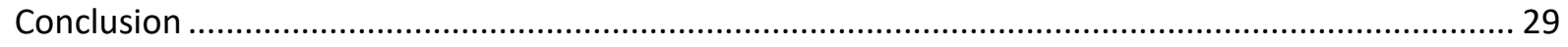

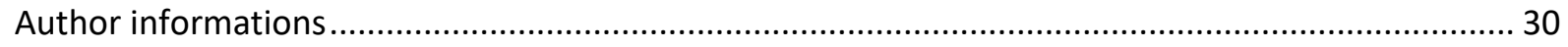

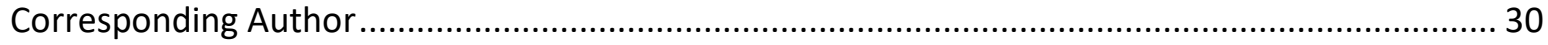

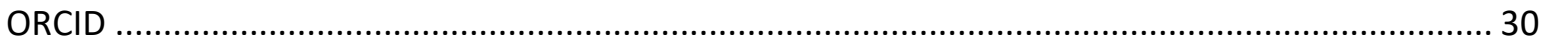

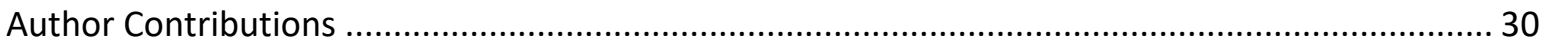

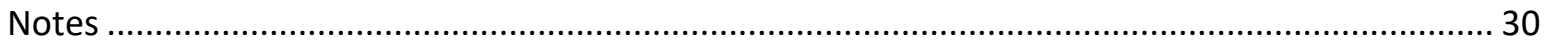

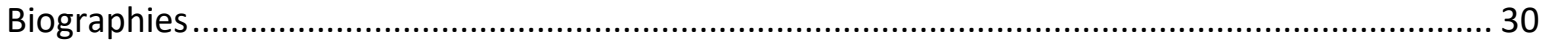

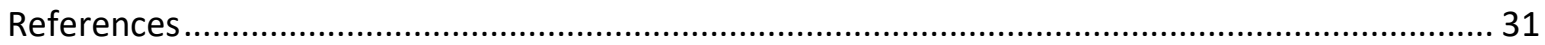

Despite the advances in the development of new instruments and highly sensitive analytical methods based on gas, liquid or supercritical fluid chromatography coupled to various detectors including high resolution mass spectrometry (MS) that can be associated with different ionization sources, a pre-treatment is usually necessary in order to extract and isolate the analytes of interest from complex samples before their determination. Solid-phase extraction (SPE) is routinely used for the extraction or purification of compounds from liquid samples or solid matrix extracts. Despite their attractive features, the classical SPE sorbents retain analytes by non-selective hydrophobic (with alkyl-bonded silicas, polymers, carbonaceous sorbents,...) or polar interactions (with silica, amino-bonded silica, alumina,...) that lead to partial co-extraction of interfering substances that may cause matrix effects even with a specific detector such as a mass spectrometer.

To enhance the extraction selectivity of the target analytes, new materials involving a mechanism of molecular recognition were developed. They include immunosorbents based on the high affinity and selectivity of antigen-antibody interactions allowing a selective extraction of the target analyte and compounds having a similar structure. ${ }^{1-4}$ Nevertheless, the development of an immunosorbent is time-consuming and relatively expensive. A similar behavior can also be obtained using aptamers, i.e. DNA or RNA sequences with high specificity towards given compounds. The resulting oligosorbents were recently successfully applied to the selective extraction of different target analytes from biological fluids and food samples. ${ }^{5-8}$ Once the sequence is available, the development of an oligosorbent is less expensive than an immunosorbent. However, despite their high potential, a limited number of sequences is, to date, available.

An alternative is to develop molecularly imprinted polymers (MIPs). These sorbents are synthetic polymeric materials possessing specific cavities designed for a template molecule involving a retention mechanism based on molecular recognition. The MIPs have been already successfully used in several fields, such as sensors, ${ }^{9,10}$ biomimetic catalyst in organic synthesis, ${ }^{11}$ drug delivery, ${ }^{12}$ and separation of structural analogs or enantiomers ${ }^{13}$ in liquid chromatography (LC) ${ }^{14-16}$ and capillary electrophoresis. ${ }^{15-18}$ 
The use of MIPs as selective sorbents for sample pretreatment was described for the first time by Sellergren and co-workers in 1994 and concerned the development of a MIP for the solidphase extraction of pentamidine from urine ${ }^{19}$, there has been a growing interest in these polymers for extraction purposes. Initially mainly developed for the selective recognition of small molecules, such as drugs, pesticides or other environmental pollutants, ${ }^{20-23}$ they are now developed, as illustrated in recent reviews, for the recognition of proteins ${ }^{24-26}$ or even microorganisms. ${ }^{27}$ While the nature of the targets for which MIPs have been developed has evolved, so has the format of the extraction devices. Indeed, although MIPs have been mainly applied to the selective extraction or cleaning of target analytes from various complex samples by introducing them in a cartridge to carry out off-line SPEs, a strong trend towards miniaturized extraction devices has been observed over the past decade. The tendency is to develop new synthesis pathways to obtain particles of controlled sizes, fibers, stir-bars or membranes thus allowing their use in dispersive SPE (dSPE), solid-phase microextraction (SPME) or stir bar sorptive extraction (SBSE). This change of format is not only a reduction in size, but also implies changing the polymerization modes, which, despite the small size of the devices, must make it possible to maintain sufficient binding capacity. The modification of the polymerization conditions is also required when developing MIPs for proteins because of their lack of stability in conventional polymerization solvents. Based on the works published over the past two years for numerous target molecules, as reported on Figure 1, this paper aims to review the new strategies of development of MIPs in different formats dedicated to various extraction methods (whose distribution in terms of published work is given in Figure 2), often treated independently in the previously mentioned reviews, for both small organic molecules and proteins for which there are high expectations for replacing antibodies.

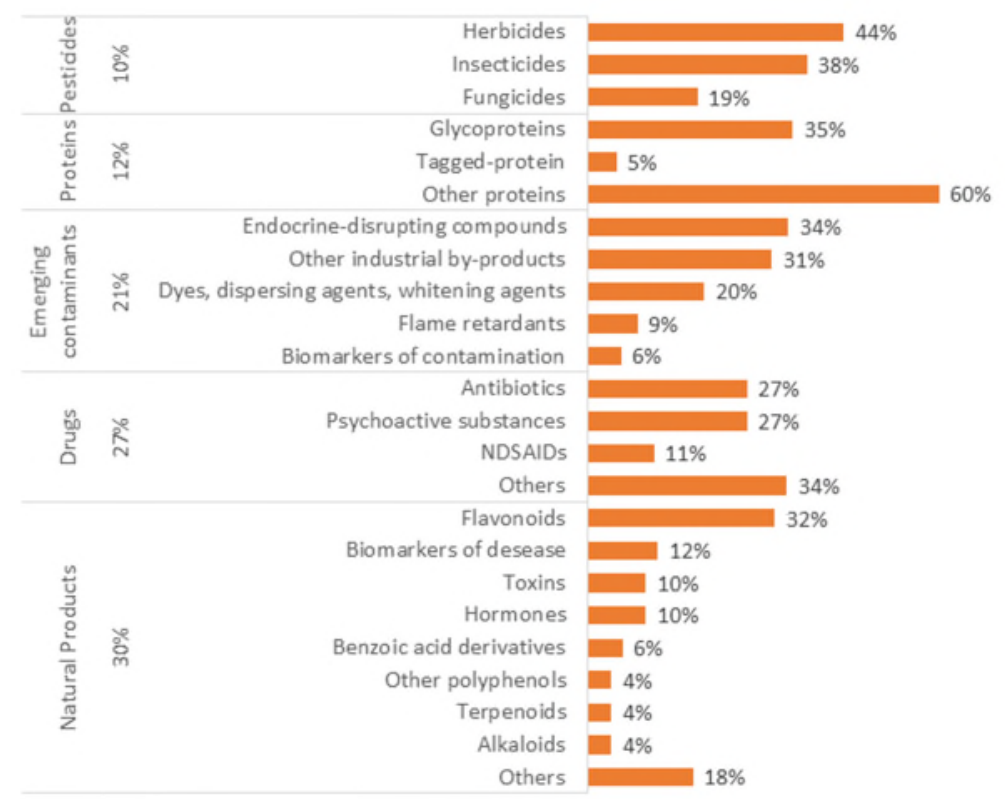

Figure 1: Groups of molecules for which MIPs have been recently developed. NSAIDs: Nonsteroidal antiinflammatory drugs. 


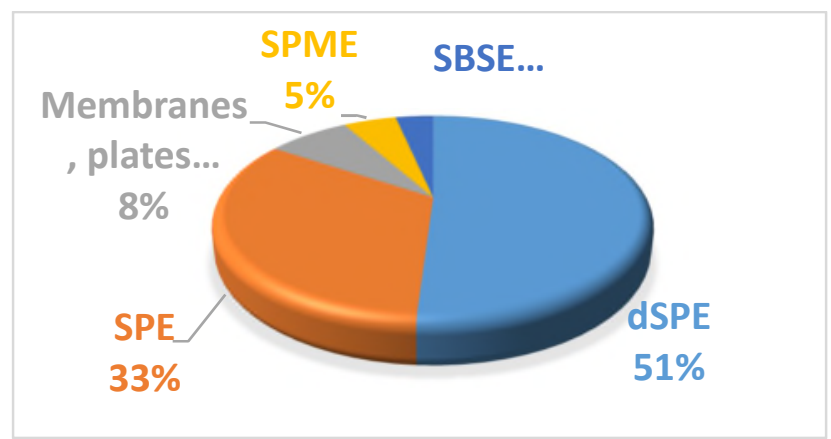

Figure 2: Distribution of extraction methods using MIPs in the works published over the past two years.

\section{Trends in polymerization methods}

\section{Choice of the reagents}

The synthesis of a MIP usually consists first in the complexation of a template molecule with functional monomers in solution, through non-covalent bonds. A cross-linker and an initiator are then introduced to generate the polymerization of the monomers around the template. After polymerization, template molecules are removed by extensive washing steps thus making available the binding sites, i.e. cavities, complementary to the template in size, shape, and position of its functional groups. MIPs are generally prepared using methacrylic acid (MAA), acrylic acid (AA), vinylpyridine (VP), itaconic acid (IA) or styrene as functional monomer and ethylene glycol dimethacrylate (EGDMA) or divinylbenzene (DVB) as cross-linker.

A non- to moderately polar and aprotic solvent, such as toluene, dichloromethane, chloroform, and acetonitrile or a mixture of them is used as porogen. Thus, polar interactions such as hydrogen bonds and electrostatic interactions can take place in these organic media. A few studies reported the use of polar and protic media, such as methanol, ethanol, and even water, for the synthesis of MIPs specific of compounds able to develop strong electrostatic interactions. ${ }^{28}$ Nevertheless, the most common approach used to produce a MIP in polar solvent is the sol-gel approach based on the use of organosilanes, mainly 3aminopropyltrimethoxysilane (APTMS), 3-aminopropyltriethoxysilane (APTES), and P phenyltrimethylsilane (PTMS), plus tetraethyl orthosilicate (TEOS) as cross-linker and by adding an acid or a basic molecule as catalyst. ${ }^{29-37}$ This approach is particularly attractive when polar compounds used as template are not soluble in organic solvents, which are traditionally used as porogen.

Other polymerization methods based on less conventional monomers were recently reported, such as the synthesis of a MIP by a condensation reaction between 1,3,5triformylphloroglucinol and 2,6-diaminopyridine (Schiff based reaction), ${ }^{38}$ between formaldehyde, melamine, and urea in the presence of a triblock copolymer of polyethylene glycol acting as porogen, ${ }^{39}$ or between formaldehyde and phenol. ${ }^{40}$ The synthesis of photoresponsive polymers prepared with azobenzene derivatives as monomers ${ }^{41}$ or thermosensitive polymers using acrylamide derivatives were also recently reported. ${ }^{42-45}$ At 
last, a mercapto-alkynyl click polymerization to produce a MIP at the surface of magnetic $\mathrm{Fe}_{3} \mathrm{O}_{4}$ nanoparticles (NPs) was reported. ${ }^{46}$

If the non-covalent approach is the most commonly used to obtain MIP extraction sorbents, as it facilitates the removal of the template molecule at the end of the synthesis, the covalent approach was recently used to produce a MIP for bisphenol A by synthesizing first a template molecule by reaction between an analog of bisphenol $A$ and an organosilane. ${ }^{47}$ This was also achieved by synthesizing a polymerizable template, a phenolic R-amphetamine sulfonamide derivative, that was combined with phenol and formaldehyde, the sulfonamide linkage being further hydrolyzed to provide cavities for the trapping of R-amphetamine. ${ }^{40}$ Boronic acid was also used for its ability to form a reversible covalent complex with cis-diol compounds such as luteolin, ${ }^{48,49}$ vitamin B12, ${ }^{50}$ sialic acid, ${ }^{51}$ or for the specific trapping of glycans of glycoproteins as discussed in more detail below.

Many works reported the screening of different synthesis conditions by preparing MIPs using different types of monomers, cross-linkers, template/monomer or monomer/cross-linker ratios, natures of the porogen, ${ }^{28,30,39,43,52-65}$ and even the $\mathrm{pH}$ when boronic acid is involved. ${ }^{50,66}$ The evaluation of the resulting MIPs consists mainly in comparing the binding capacity of the MIP for the target analyte with the one obtained with the corresponding non-imprinted polymer (NIP) synthesized with the same conditions as the MIP but in the absence of the template molecule. To limit the number of MIPs to be prepared and characterized, a computational approach was as an help to select the monomer or template/monomer ratio. ${ }^{67-}$ 69

A MIP is usually synthesized for a specific analytical use that implies the choice of a given template molecule, whose the structure and the functionalities define the subsequent properties of the binding sites. In most of the cases, the molecule selected as template is the molecule that has to be extracted next by the MIP thus ensuring an optimal recognition during the extraction process. The selection of the template is also particularly crucial when the objective is to develop a MIP for class-selective extraction, such as it was the case for natural products, ${ }^{70,71}$ antibiotics, ${ }^{60,72,73}$ drugs, $^{74-77}$ industrial products, ${ }^{38,68,78,79}$ pesticides, ${ }^{30,54,80,81}$ and estrogen receptor-active compounds. ${ }^{82-85}$ To improve the ability of the polymer to selectively trap as many structural analogs as possible, a mixture of two templates was reported for the trapping of four plant growth regulators, ${ }^{86}$ six phthalate esters ${ }^{33}$ or seventeen triazines. ${ }^{87} \mathrm{~A}$ mixture of two target molecules was also used as template for their simultaneous extraction from real samples. ${ }^{61,65,88}$

The complete removal of the template molecules from the MIP is difficult to achieve and necessitates extensive washing steps with large volumes of organic solvents in basic or acidic conditions. Recently, the efficiency of Soxhlet extraction and ultrasound to remove the template was compared, showing the higher efficiency of ultrasound to remove hydroxybenzoic acid from the MIP. ${ }^{89}$ The use of a dummy molecule as template, i.e. a compound that resembles the target analyte in terms of shape, size, and functionalities and that can be selected by computational approach, ${ }^{90}$ prevents from the risk of residual template leakage from the polymer, thus causing false quantification when it is applied to trace analysis. This 
can be illustrated by a recent work related to the application of a MIP for the selective extraction of carbamazepine (CBZ) at trace level in river water. ${ }^{91} \mathrm{CBZ}$ and methoxyCBZ, taken as dummy molecule for the MIP synthesis as it is never recovered in real waters, were detected in the elution fraction of the MIP at a concentration level of 80 and $1010 \mathrm{ng} . \mathrm{L}^{-1}$, respectively. The presence of methoxyCBZ resulted from its leakage from the MIP during the extraction procedure. This concentration represents only $0.000047 \%$ of the amount of the template molecule introduced during the synthesis. Even if this value remained low, it clearly demonstrates the importance of the use of a structural analog as template during the MIP synthesis in order to avoid false positive responses during its subsequent use, particularly when trace level concentrations are investigated. In addition to this advantage, the dummy approach was also considered for an expensive or difficult-to-achieve template molecule. ${ }^{29,55,90-93}$

\section{Towards green approaches}

Several groups also put forward the necessity to develop greener synthesis approaches, by using water as porogen. In this way, MIPs were produced in aqueous media using different types of monomers such as dopamine, ${ }^{94,95}$ chitosan, ${ }^{96,97}$ acrylamide derivatives, ${ }^{98}$ melanine and resorcinol combined with methylenetetramine, ${ }^{64}$ nylon- $6^{99,100}$ or aniline. ${ }^{101,102}$ To provide a green synthesis process, another approach consists in preventing the direct use of a toxic cross-linking agent by producing it directly in the polymerization solution, such as it was done for formaldehyde through the hydrolysis of hexamethylenetetramine.$^{55}$ The use of ionic liquids as monomer $28,73,80,88$ or porogen ${ }^{103,104}$ can also be considered as a greener approach than the used of conventional monomers. Deep eutectic solvents (DESs) are also considered as a greenlike material. They resemble ionic liquids with low vapor pressure, low toxicity, good biocompatibility, and good biodegradability with an easier preparation than that of ionic liquid. DESs were used as monomers for the synthesis of MIPs specific to transferrin, ${ }^{105}$ bovine hemoglobin, ${ }^{106}$ quercetin, ${ }^{107}$ and catechins. ${ }^{108}$ A DES whose composition had to be optimized to adapt its liquid state and viscosity ${ }^{107}$ was also used both as template and monomer for the synthesis of a MIP for 3,4-dihydroxybenzoic acid. ${ }^{109}$

\section{Synthesis of MIPs for proteins}

While many applications of MIPs in the field of extraction have mainly focused on small molecules, their development in recent years for the protein extraction has grown very rapidly. These MIPs were mainly synthesized in aqueous media, for example by cryopolymerization for myoglobin ${ }^{110}$ or using water soluble reagent such as melanine and resorcinol as monomers and methylenetetramine as cross-linker for bovine serum albumin (BSA). ${ }^{64}$ Dopamine for horseradish peroxidase (HRP) ${ }^{111}$ and metallothionein, ${ }^{95}$ aniline for ovalbumine (OVA), ${ }^{102}$ and DES for bovine hemoglobin ${ }^{105,106}$ were also recently used as monomers. The synthesis of imprinted silica materials by sol-gel approach using organosilanes 35,112 or a mixture of organic monomers and organosilanes ${ }^{113}$ was also proposed. It was achieved using water soluble and photo-switchable monomers such as azobenzene 
derivatives ${ }^{114}$ or preparing thermo-sensitive polymer using $\mathrm{N}$-isopropylacrylamide (NIPAM) ${ }^{44}$ A similar approach was proposed to prepare a MIP for other macromolecules, heparin oligosaccharides. ${ }^{43}$

To enhance the affinity of MIPs towards glycoproteins, many authors proposed the use of boronic acid. As an example, this ligand was first immobilized onto core particles and put in contact with the target protein that was trapped by its glycan residues before initiating the polymerization around the protein. This was done for transferrin that was immobilized on boronic acid-functionalized NPs to achieve an oriented surface imprinting by selfpolymerization of either 2-anilinoethanol or 4-aminobenzylalcohol around the immobilized template. ${ }^{66} \mathrm{~A}$ similar approach was applied to OVA, the MIP layer being produced by a redox polymerization of aniline around the immobilized template. ${ }^{102} \mathrm{~A}$ combination of boronic acid and dopamine was also proposed to develop a MIP for OVA. ${ }^{115}$ The grafting of boronic acid on the surface of a particle was also used to trap HRP protein by its glycan moieties before the synthesis of a MIP layer in the presence of an organosilane or aniline around the particle. ${ }^{111,112}$ The in situ digestion of the protein using trypsin and then pronase $\mathrm{E}$ was also proposed to isolate glycan-linked short peptides further used as templates to produce a MIP toward this glycoprotein. ${ }^{112} \mathrm{~A}$ schematic diagram of this approach is reported on Figure 3 . The use of metal chelation to immobilize the protein onto NPs before initiating the surface imprinting in the presence of a boronic acid derivative was also proposed for selective trapping of OVA. ${ }^{71}$

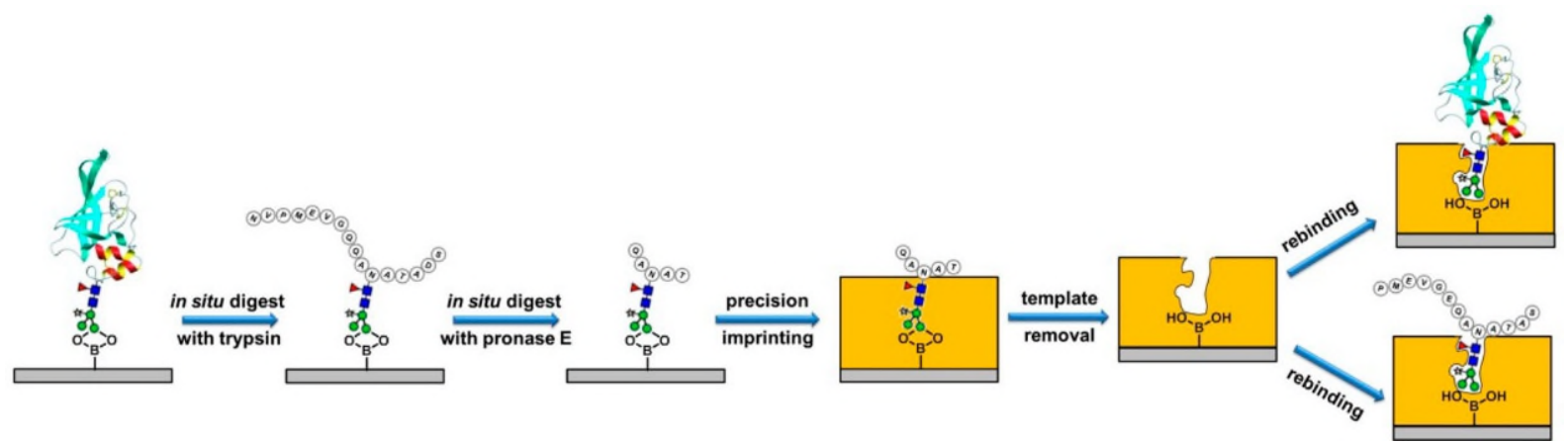

Figure 3: Schematic diagram of the precision imprinting strategy by combining the in situ dual enzymatic digestion and boronate affinity controllable oriented surface imprinting approach, Reproduced from Bie, Z.; Xing, R.; He, X.; Ma, Y.; Chen, Y.; Liu, Z. Anal. Chem. 2018, 90 (16), 9845-9852 (Ref ${ }^{112}$ ). Copyright 2018 American Chemical Society.

MIPs for proteins or large peptides can also be prepared using the epitope approach. Indeed, a nonapeptide fragment derived from the $\mathrm{C}$-terminus domain of cytochrome $\mathrm{C}$ was used as template molecule to prepare a MIP specific to Cytochrome $\mathrm{C}$, by conventional radical polymerization of MAA and EGDMA in organic solvent. ${ }^{116}$ The epitope approach was also used to prepare a MIP for amanitine, an octopeptide, by thiol-ene click reaction in an organic solvent. ${ }^{117}$ A similar approach using dual-template epitope, i.e. C- and N-terminal peptides of the targeted protein, and combining metal chelation and distillation precipitation was also proposed. ${ }^{118}$ At last, the synthesis of a MIP using a tetrapeptide DYKD contained in the FLAG epitope (DYKDDDDK) used to tag proteins was developed to purify tagged proteins from crude 
cell lysates, the epitope approach again allowing the use of conventional monomers and organic porogen for the MIP synthesis. ${ }^{119}$

\section{MIP in SPE}

In the extraction field, MIPs were initially mainly developed in SPE format ${ }^{120}$ and several ones are already commercially available. The principle of SPE with MIP is the same as with conventional SPE sorbents. The MIP particles (60 to $400 \mathrm{mg}$ ) are packed into disposable cartridges between two frits. Some works recently reported the introduction of 5-70 mg of MIP particles in $100-1000 \mu \mathrm{L}$ pipette tips ${ }^{29,39}$ or of $2 \mathrm{mg}$ into the needle of a syringe. ${ }^{109}$ After a conditioning step, the sample is percolated through the MIP and a washing solution can be applied to remove the interfering compounds that are not strongly retained by the MIP cavities. The desorption of analytes is achieved by percolating a solvent able to develop interactions with the sorbent inducing the elution of the analytes.

\section{Preparation of MIP for SPE}

Most of the reported MIPs were prepared in bulk, by far the most widely used method owing to its simplicity. ${ }^{20}$ The bulk polymer monolith is then crushed, ground, and sieved to obtain particles, with a non-regular shape, mainly in the $25-100 \mu \mathrm{m}$ size range. A sedimentation step is then achieved to remove fine particles.

Particles of MIP can also be directly obtained by precipitation polymerization that takes place in the presence of a larger amount of porogen (typically 2 to 10 times higher than for bulk polymerization). ${ }^{54-56,87,90,121,122}$ As the polymerization proceeds, the growing polymer chains become insoluble in the liquid phase and precipitate. Micro- or nanospheres can be generated when accurate control of the parameters governing the precipitation polymerization is achieved (i.e. temperature, cross-linker nature ...). Then, RAFT was recently combined with reflux precipitation polymerization to obtain water-compatible MIP particles for sulfonamides. ${ }^{123}$

MIPs can also be obtained by suspension polymerization that consists in the introduction of the organic-based polymerization mixture as droplets into an excess of a continuous dispersion phase (water or perfluorocarbon fluids) by agitation in the presence of a stabilizer (suspending agent), each droplet acting as a mini bulk reactor. This method is suited for the production of spherical beads in a broad size range from a few micrometers up to a few millimeters. In return, the polymerization mixture must contain higher molar concentrations of template and monomers to compensate the partial loss of these reagents in the dispersion phase. Inversed suspension polymerization was recently reported, the polymerization solution being drop-wise in an $n$-heptane solution containing a surfactant. ${ }^{57}$ Pickering emulsion using silica was also proposed to produce particles in the $19-44 \mu \mathrm{m}^{124}$ or $30-80 \mu \mathrm{m}$ range $^{82}$ that are well-adapted to the flow-rate of liquids during the extraction process in a SPE cartridge. 
In order to better control the size distribution and shape of the MIP particles, while decreasing the amount of waste materials, polymerization methods based on the coating of preformed particles (with a more or less uniform size) was reported to produced SPE sorbents. They consist of the dispersion of these cores in the MIP polymerization solution, containing the monomer, the template, and the cross-linking agent. These particles can be silica particles of various sized ${ }^{73,125,126}$ or mesoporous silica spheres ${ }^{104,127}$ (that can also be used as sacrificial supports) ${ }^{119,128}$ polystyrene beads, ${ }^{129}$ polystyrene-divinylbenzene beads, ${ }^{28}$ or polymeric cores prepared by dispersion polymerization. ${ }^{130}$ To improve the rigidity of the MIP particles while increasing the adsorption capacity, polyhedral oligomeric silsesquioxanes were combined with nano mesoporous molecular sieve thus providing a dendritic effect. ${ }^{104}$ A MIP was also recently produced by combining graphene oxide $(\mathrm{GO})$ selected for its high surface area and $\beta$ cyclodextrin to enhance its adsorption capacity. ${ }^{131}$ At last, to increase the flow-rate of percolation for large sample volumes, a mix of MIP particles and filter paper pulp was placed between commercial cellulose filters to prepare a disk of paper-based MIP of $47 \mathrm{~mm}$ of diameter. This disk was used as a MIP-SPE cartridge, the large size diameter allowing the percolation of a large volume $(300 \mathrm{~mL})$ of water at a high flow-rate $(30 \mathrm{~mL} / \mathrm{min}) .{ }^{132}$

The direct in situ synthesis of a monolith by bulk polymerization to prepare different extraction devices, thus avoiding the grinding step, were also recently reported. A monolith was directly prepared in a $100 \times 4.6 \mathrm{~mm}$ stainless steel column using ionic liquid as porogen to control the monolith permeability ${ }^{103}$ or in a $8 \mathrm{~cm} \times 530 \mu \mathrm{m}$ internal diameter capillary using acryloyl- $\beta$ cyclodextrin and MAA as dual-functional monomers and in the presence of silanized multiwalled carbon nanotubes (CNTs), to enhance the specific surface area of the resulting sorbent. ${ }^{133}$ A MIP monolith prepared in a 6-mL cartridge in the presence of GO particles was also recently proposed. ${ }^{88}$ Permeable monolithic MIPs were also obtained in a 2-mL extraction cartridge by the in situ synthesis with a sol-gel approach. ${ }^{72}$ The production of MIP particles by emulsion polymerization in a cryogel directly into a cartridge reservoir was also recently reported to circumvent the problem of high back pressure generated by small-size particles. ${ }^{134}$ The direct in situ synthesis of a permeable monolith in a $200 \mu \mathrm{L}$-pipette tip by adding dodecanol as porogen in toluene was also reported. ${ }^{60}$ Obtaining a good permeability by optimizing the proportion of porogen; i.e. dodecanol, in acetonitrile was also the objective of Bouvarel et al. when synthesizing a monolithic MIP in situ in a $100 \mu \mathrm{m}$ internal diameter fused-silica capillary for its further on line coupling with nanoLC. ${ }^{135}$

The scanning electron microscopy (SEM) pictures of the resulting different types of MIP sorbents used in SPE, are reported on Figure 4. If the shape of the MIP particles prepared by bulk polymerization depends on the grinding and sedimentation process, the size of the particles generated by precipitation polymerization, coating of a core sorbent or Pickering emulsion strongly varies, which has a strong impact on the MIP flow-through properties during the SPE procedure. For in situ synthesis, the perfect anchoring of the MIP to the surface of the device chosen for its synthesis (pipette tip, capillary...) as well as a sufficient permeability of the monolith to limit back pressure during sample percolation have to be controlled. 

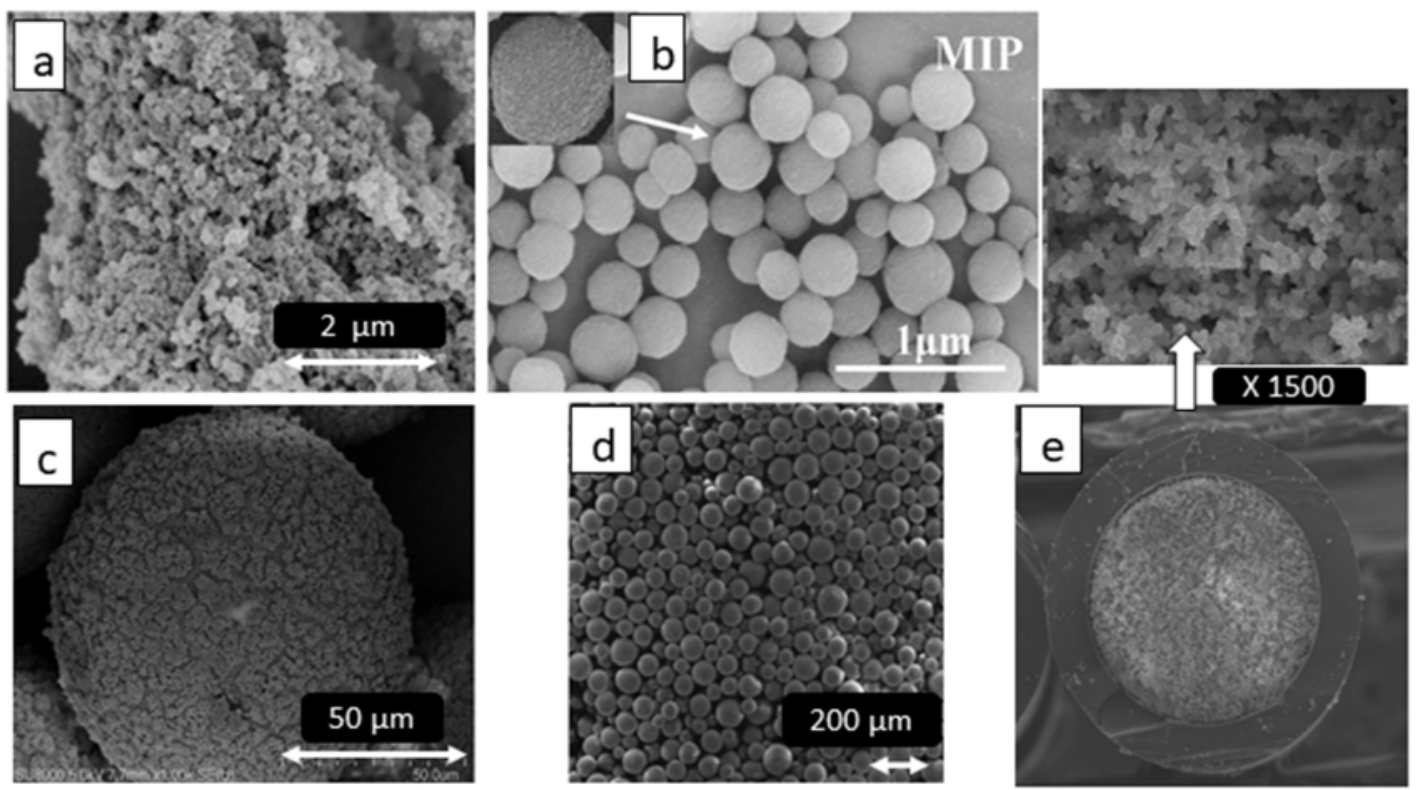

Figure 4: MIP sorbents used in SPE and obtained by various approaches of synthesis: (a) surface of particles obtained by bulk polymerization; (b) precipitation polymerization; (c) MIP layer coating of polystyrene divinyl benzene beads; (d) Pickering emulsion; (e) in situ synthesis of a monolith in a $530 \mu \mathrm{m}$ internal diameter capillary. Reproduced from (a) Sorribes-Soriano, A.; Esteve-Turrillas, F. A.; Armenta, S.; Amorós, P.; Herrero-Martínez, J. M. Anal. Chim. Acta 2019, 1052, 73-83 (ref ${ }^{74}$ ); (b) Li, Z.; Qian, Z.; Hu, S.; Gong, T.; Xian, Q. Chemosphere 2018, 212, 872-880 (ref ${ }^{90}$ ). (c) Zhu, G.; Cheng, G.; Wang, P.; Li, W.; Wang, Y.; Fan, J. Talanta 2019, 200, 307-315 (ref ${ }^{28}$ ) (d) Tang, J.; Wang, J.; Yuan, L.; Xiao, Y.; wang, X.; Yang, Z. Steroids 2019, 145, 23-31.(ref ${ }^{82}$ ); (e) Liang, G.; Guo, X.; Tan, X.; Mai, S.; Chen, Z.; Zhai, H. Microchem. J. 2019, 146, 1285-1294 (ref ${ }^{133}$ ). Copyright 2018 and 2019, with permission from Elsevier.

\section{Applications of MIP-SPE}

MIP-SPE was recently applied to the trace analysis of target analytes, mainly pesticides, industrial contaminants, and drugs, from real waters, 28,81,83,90-92,131,132,134,136 soil and sediment extracts, ${ }^{67,73}$ and food extracts or beverages. . $^{38,54,60,72,82,87,123,124,129,130,133,137,138}$ It was also used to extract natural products from food or plants $39,55-57,70,86,103,121,127,139$ to control their occurrence, such as for toxins, or to purify them. It was also largely applied to the

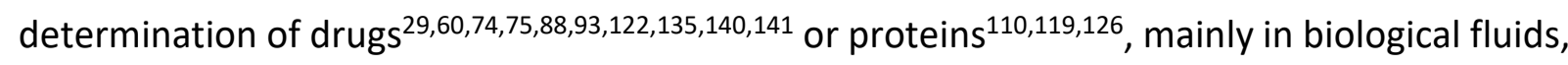
and of various compounds in manufactured products. ${ }^{125,128}$

Aqueous samples are often filtered before their percolation through the MIP. For more complex samples, such as biological fluids, different methods were reported to limit the risks of matrix effects during this percolation step. This can consist of a simple dilution of the sample with a buffer, a centrifugation step or a precipitation of the proteins (further removed by centrifugation), which can be also followed by a liquid-liquid extraction (LLE) procedure..$^{54,122}$ For solid samples, the final dry extract is often diluted in the solvent used for the MIP synthesis, that should favor the selective interactions, or in a buffer. A preliminary purification step by LLE ${ }^{30}$ or on conventional SPE sorbent was also reported. ${ }^{103,124}$ 
If MIP can be applied to the purification of a target analyte from low sample volumes of biological fluids or extracts from solid matrices, they can also be used to selectively concentrate target analytes from samples. Indeed, enrichment factors (EFs) between 50 to 2000 can be calculated from papers describing the percolation of $500 \mathrm{~mL}^{129}$ to $1 \mathrm{~L}^{90,92}$ of the sample and a final volume of the extract of $0.2-0.5 \mathrm{~mL}$.

\section{Optimization of the SPE procedure}

In MIP-SPE as with conventional SPE sorbents, different parameters have to be optimized, particularly when high EFs are expected, such as the amount of sorbent and the composition and volume of the sample to avoid breakthrough of the target analyte. Several studies reported the existence of an optimal $\mathrm{pH}$ range to favor electrostatic interactions between the ionized form of the monomer residues and the basic or acidic analyte, thus improving the extraction recoveries. ${ }^{75,90,92,110,131}$ The effect of temperature on the MIP retention capacity was also reported for protein extraction, as the use of a basic aqueous saline solution for elution to replace organic solvents generally used to desorb the small organic molecules. ${ }^{110}$ Many works reported the optimization of these different parameters to obtain high extraction recoveries on MIPs. ${ }^{75,88,90,122,123,127,128,131}$ Nevertheless, when using a MIP, the objective is to reach an optimal selectivity. Therefore, the study in parallel of the extraction recoveries of the target analyte on the NIP must be done during the optimization of the extraction parameters, as it is often the case. ${ }^{39,55,60,72,74,81,81,90-93,110,124,135,136,140}$ These recoveries must be as low as possible on NIP to ensure that the retention on MIP is mainly due to the presence of specific cavities and then to ensure an optimal selectivity. A control molecule with a different structure from the target analytes(s) can also be studied on both sorbents. This was done recently by Shao et al. who prepared a MIP for the selective extraction of fluoroquinolones (FQs) from infant formula powders. ${ }^{72}$ In order to evaluate the selectivity of the MIP, a mixture containing 6 FQs and a control compound was tested. The MIP showed a good capture ability for the six FQs with recoveries ranged from 84.3 to $96.0 \%$, while the recoveries on the NIP was only around $30 \%$. For the control compound, very similar recoveries (around $36.2 \%$ ) were observed on both MIP and NIP. The higher recoveries for FQs on the MIP than on the NIP and the low retention of the control molecule confirmed both the specific recognition generated by the imprinted cavities.

\section{MIP-SPE performances}

The validation of analytical methods involving MIP as SPE sorbent was achieved by the calculation of day-by-day and inter-day recoveries and by the estimation of the LOD and LOQ in real samples, ${ }^{30,38,60,72,81,82,93,125,130,140}$ which is a real evolution these last years. Indeed, previous works mainly reported the measurement of recoveries in a single spiked sample. The reproducibility of the synthesis was only recently reported, when comparing results from different batches for a MIP prepared by combining reversible addition-fragmentation chain 
transfer (RAFT) with reflux precipitation polymerization (RPP) ${ }^{123}$ and for a MIP monolith synthesized in situ in a $100 \mu \mathrm{m}$ capillary. ${ }^{135}$

MIP-SPE methods were also evaluated by comparing the extraction recoveries obtained using the MIP and other commercially available SPE sorbents $30,39,60,92,131$ or obtained with methods such as QuEChERS for food samples. ${ }^{137}$ The comparison with conventional SPE sorbents was also carried out to demonstrate the selectivity brought by the MIPs. Indeed, the removal of matrix components from final extracts with MIPs gave rise to a cleaner baseline in UV ${ }^{81}$ or fluorescence ${ }^{39}$ and a higher sensitivity (higher $\mathrm{S} / \mathrm{N}$ ratios in $\left.\mathrm{MS}\right)^{91}$ than using conventional sorbents. They also allow to limit ion suppression effect in $\mathrm{MS} .{ }^{83}$ It was also recently reported that the potential remaining matrix effects were reduced with MIPs in comparison with conventional sorbents. ${ }^{30,82,93,123}$

The clean extracts obtained by MIP-SPE are usually analyzed by chromatographic methods (mainly LC or gas chromatography -GC-) associated to various types of detectors. Owing to the high clean-up effect brought by the MIP, these methods were sometimes replaced directly by ion mobility spectrometry (IMS) to shorten the analysis duration. ${ }^{132,137,140}$ The direct online coupling of a MIP with MS was also recently described, allowing thus a complete automation of the entire analytical procedure. In this case, MIP particles were packed in a precolumn $(10 \times 4.6 \mathrm{~mm})$ connected to a LC switching valve and, after the transfer of the sample via a loop through the MIP, the desorption of the target analyte was achieved by a solution that allows both effective desorption and ionization in MS. This was done for the extraction of tricyclic antidepressants from diluted serum, their identification being ensured by a triple-quadrupole mass analyzer. ${ }^{141}$ To limit interferences, the MIP was coated with BSA allowing the exclusion of proteins during the extraction procedure. As previously mentioned, the high selectivity brought by a MIP can also be ensure by a careful optimization of the SPE procedure by comparing the retention on MIP and on MIP in real media. This was done for the extraction of cocaine from biological fluids, plasma and saliva, on a miniaturized on-line set-up by coupling of a MIP monolith (prepared in a $100 \mu \mathrm{m}$ diameter capillary) on line with reversed phase nanoLC-UV (see the scheme on the top of Figure 5). As illustrated by the chromatograms on Figure 5, the very clean-baseline obtained using the MIP and the lack of retention of cocaine using the NIP highlight the high selectivity brought by the MIP that allows the easy determination of the cocaine analyte in this plasma with a limit of quantification of $14.5 \mathrm{ng} / \mathrm{mL}$ with UV detection while injecting $100 \mathrm{~nL}$ of a diluted plasma sample. ${ }^{135}$ 


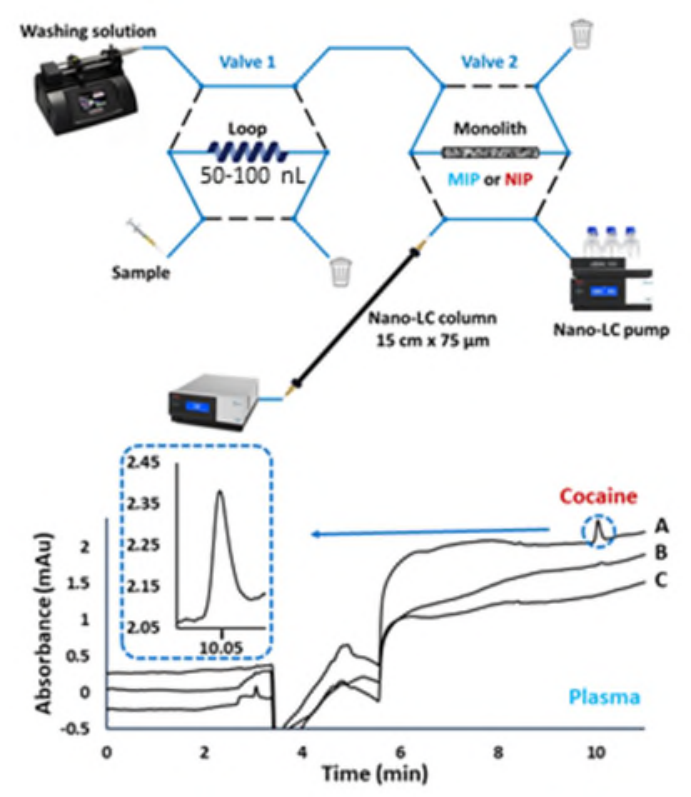

Figure 5: Set-up of the on-line coupling of the monolithic MIP/NIP (50 mm x $100 \mu \mathrm{m}$ i.d.) with nanoLC-UV (Top) and chromatograms obtained after the extraction on MIP (a) and NIP (b) of $50 \mathrm{~nL}$ of plasma spiked with cocaine (equivalent to $100 \mathrm{ng} \mathrm{mL}^{-1}$ in plasma) compared to the blank plasma (c) on MIP. Reproduced from Bouvarel, T.; Delaunay, N.; Pichon, V., Anal. Chim. Acta 2019. https://doi.org/10.1016/j.aca.2019.10.046 (Ref ${ }^{135}$ ). Copyright 2019, with the permission from Elsevier.

The removal of matrix components also enabled the direct analysis of the MIP elution fraction by UV detection, ${ }^{103,138}$ amperometry, ${ }^{29}$ by assays that are often affected by matrix effects, such as an immunochromatographic assay, ${ }^{136}$ or by assays measuring the bioactivity of an extract containing natural products ${ }^{70}$ or the activity of compounds towards estrogen receptors. ${ }^{83}$ A recent example reported by Yagishita et al. illustrates perfectly the interest of MIP to remove the matrix effect that can affect the response of sophisticated and expensive instruments such as MS or bioassays. ${ }^{83}$ Indeed, they synthesized a MIP for the selective extraction of estrogen receptor(ER)-active compounds from surface water and they compared the chromatograms obtained by the LC-MS analysis of the fractions concentrated with a conventional styrene-divinylbenzene (SDB) sorbent or the MIP (defined as SDB-Conc, MIPConc, respectively). They also analyzed the solution recovered after percolation on the MIP that contained the non-retained compounds (defined as MIP-Pass) (see Figure 6). Pictures of the tubes containing these different concentrated fractions show that most of the colored compounds in SDB-Conc are also present in the MIP-Pass fraction, which demonstrates that they are interfering compounds not retained by the MIP cavities. The ER activity values measured with the bioassay for each fraction, also reported on Figure 5 show that some ERactive compounds were detected in both SDB-Conc and MIP-Conc. The detected concentration was much higher in MIP-Conc than in SDB-Conc, with values of 3.7 and $3.1 \mathrm{ppt}$, respectively, whereas the activity of the MIP-Pass fraction was 0 . All these data showed that the MIP decreased interference by ion suppression in LC-MS and identified the presence of a 
few ER-active compounds, which could not be detected by commonly used hydrophobic sorbents. $^{83}$

In addition to these performances, the greenness of an analytical method involving a MIP was recently evaluated by giving penalty points while considering solvent or energy consumption. ${ }^{137}$ At last, in order to reduce the analytical cost, the reusability of some MIP was evaluated showing the possibility to use them $5,70,131,1406,12710,{ }^{139} 12,{ }^{110} 20^{38,60}$ to 25 times ${ }^{87}$ without observing a loss of recovery higher than $5 \%$.

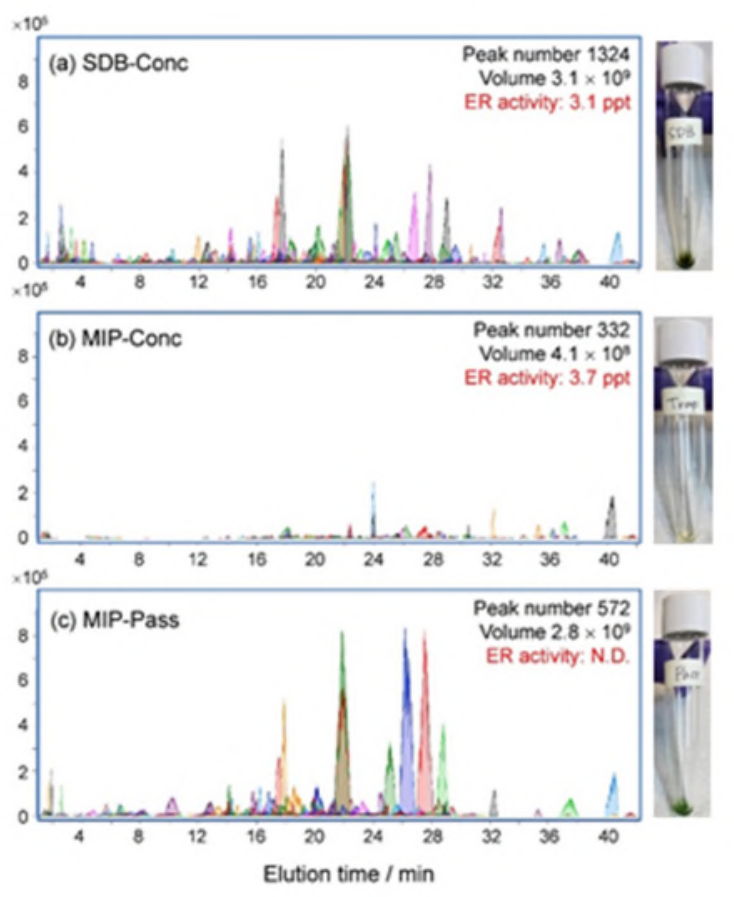

Figure 6: LC-MS chromatograms of the environmental water sample and physical appearance of the fractions (a) concentrated by SDB cartridge, (b) concentrated by MIP, (c) collected after the percolation of the sample through the MIP (non-retained compounds). Each chromatogram corresponds to the overwriting signals of all the peaks of the detected compounds. Reproduced from Yagishita, M.; Kubo, T.; Nakano, T.; Shiraishi, F.; Tanigawa, T.; Naito, T.; Sano, T.; Nakayama, S. F.; Nakajima, D.; Otsuka, K. Chemosphere 2019, 217, $204-212$ (ref ${ }^{83}$ ). Copyright 2019, with the permission from Elsevier.

\section{MIP in dispersive SPE (dSPE)}

The use of MIPs in dSPE has increased significantly in recent years, accounting for $53 \%$ of the works published in the field of MIP extraction in the last 18 months. In this case, the extraction is carried out by introducing a given amount of MIP particles into the sample. After a sufficient extraction time under stirring, the particles are recovered mainly by centrifugation or magnetic field (if magnetic core particles are used) and then introduced into a suitable desorption solvent after a possible washing step. ${ }^{142}$ MIP-dSPE can be achieved using conventional beads, magnetic beads but also NPs. As with conventional dSPE sorbents, the key-parameters to be optimized are the sample volume/sorbent amount ratio, the volume 
and nature of desorption solvent, but also the extraction time, the stirring rate, and the desorption time.

\section{Preparation of the MIP particles}

As for MIP-SPE, MIP particles for dSPE can be obtained by bulk polymerization that gives a monolith that must be crushed and possibly sieved. ${ }^{53,58,64,143-146}$ More homogenous MIP microspheres can also be obtained by precipitation polymerization, ${ }^{63,65,147-149}$ suspension polymerization, ${ }^{45,89}$ and emulsion polymerization. ${ }^{150}$

Another option is surface imprinting, which mainly consists in dispersing a core sorbent in the polymerization solution as described in detail in recent reviews. ${ }^{151,152}$ With this approach, the recognition sites are located on the surface of the supporting material, thus displaying a sufficient binding capacity, a fast mass transfer, and rapid binding kinetics due to the easy accessibility of the analytes to the binding sites. ${ }^{153}$ In the recent works, these core sorbents were activated- $\mathrm{SiO}_{2}$ microspheres or NPs, ${ }^{31,32,66,101,115-117,154,155}$ hollow mesoporous silicas, ${ }^{47}$ carboxyl-activated polystyrene colloids, ${ }^{100} \mathrm{ZnO}$ NPs coated with $\mathrm{SiO}_{2}$ and further vinilyzed, ${ }^{156}$ poly(styrene-glycidyl methacrylate (GMA)) NPs, ${ }^{71}$ tryptamine-activated sepharose beads ${ }^{35}$ or vinilyzed GO nanosheets. ${ }^{157} \mathrm{~A}$ poly(GMA) grafted on a styrene macroporous resin was also put in contact with the template and a diamine thus providing an imprinting process synchronized with a cross-linking method. ${ }^{158}$

$\mathrm{Fe}_{3} \mathrm{O}_{4}$ microspheres coated with a silanized carbon shell $\left(\mathrm{Fe}_{3} \mathrm{O}_{4} / \mathrm{C}\right)$ also served as core sorbent to produce MIP particles, the hollow surface of the MIP being then generated by dissolving the $\mathrm{Fe}_{3} \mathrm{O}_{4} / \mathrm{C}$ microspheres that served as sacrificial material. ${ }^{159} \mathrm{~A}$ similar approach consisted in the use of silica nanospheres, the hydrolysis of the $\mathrm{SiO}_{2}$ cores giving rise to a hollow shell structured MIP of $480 \mathrm{~nm}$ diameter with a shell thickness of $40 \mathrm{~nm} \cdot{ }^{41}$ A zeolite imidazolate framework-8 (ZIF-8) was used as a stabilizer and sacrificial material in a Pickering emulsion polymerization procedure, the further dissolution of ZIF-8 leading to hollow spherical polymer microspheres too. ${ }^{160}$ Some examples of particles that were prepared by some of these different approaches are reported on Figure $7 \mathrm{a}-\mathrm{d}$. Those various procedures gave rise to particles of different sizes whose homogeneity was studied for three of them. Indeed, the size of particles prepared by suspension, precipitation polymerization or by using $\mathrm{SiO}_{2}$ nanosphere as a core were in the range 1-8 $\mu \mathrm{m}, 100-350 \mathrm{~nm}$, and 20-250 nm, respectively. 

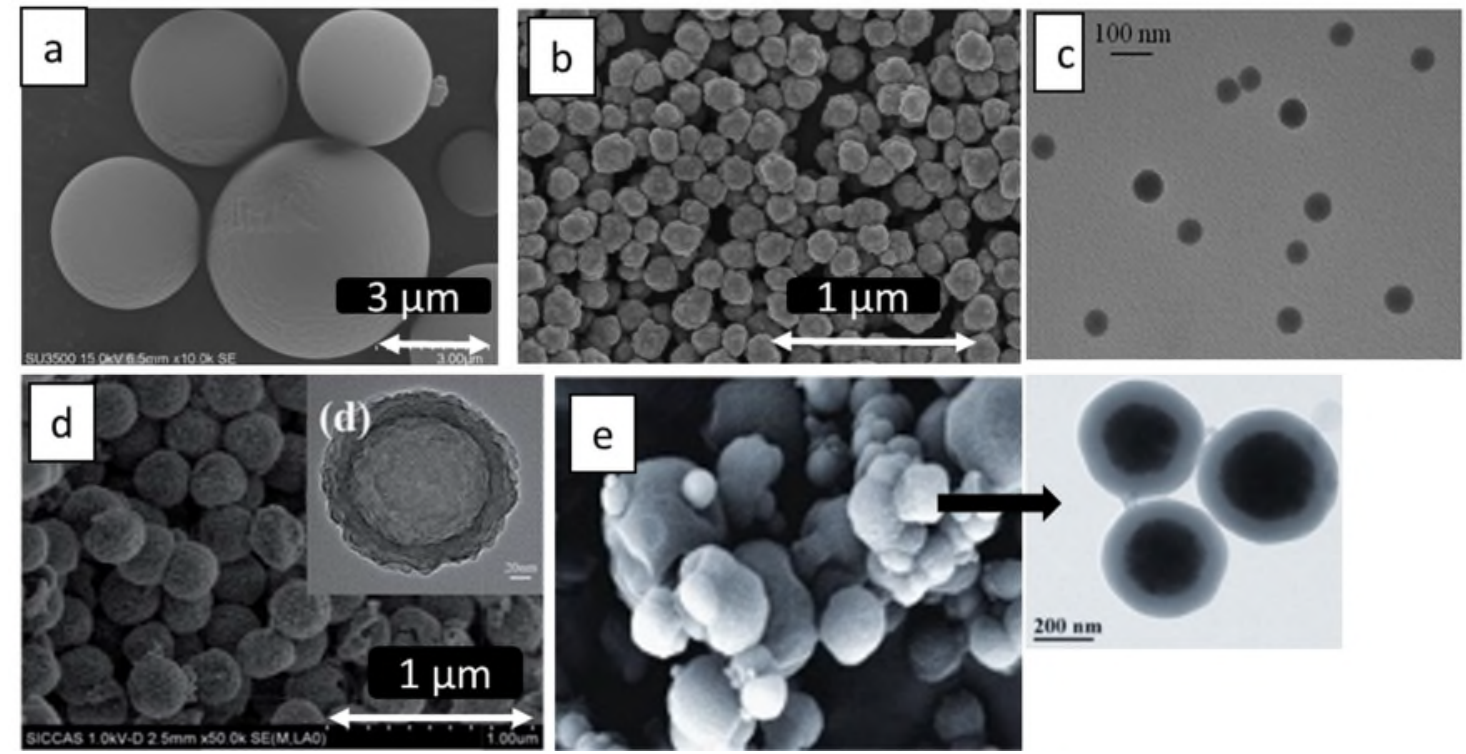

Figure 7: Non-magnetic particles prepared for dSPE by (a) suspension polymerization, (b) precipitation polymerization, polymerizing a MIP layer on (c) $\mathrm{SiO}_{2}$ nanosphere or (d) a hollow mesoporous silica surface and (e) SEM (and TEM in insert) picture of magnetic MIP particles produced using $\mathrm{Fe}_{3} \mathrm{O}_{4} @ \mathrm{SiO}_{2} \mathrm{NPs}_{\text {as }}$ core particles. Part (a) reproduced from Liu, X.; Wu, F.; Au, C.; Tao, Q.; Pi, M.; Zhang, W. J. Appl. Polym. Sci. 2019, 136 (3), 46984 (ref ${ }^{89}$ ) - Copyright 2019, with the permission of John Wiley and Sons; Part (b) (c) and (d) reproduced from Lu, W.; Liu, J.; Li, J.; Wang, X.; Lv, M.; Cui, R.; Chen, L. Analyst 2019, 144 (4), 1292-1302 (Ref ${ }^{65}$ ), from Li, D.; Tu, T.; Wu, X. Anal. Methods 2018, 10 (36), 4419-4429. (Ref ${ }^{66}$ ) and from (d) Li, L.; Yu, K.; Tian, M.; Wang, Y.; Zhang, Z.; Jiang, G.; Li, L. Anal. Methods 2018, 10 (32), 3926-3932. (Ref ${ }^{47}$ ) respectively by permission of the Royal Society of Chemistry; Part (e) reproduced from Zhang, Y.-Z.; Zhang, J.; Tan, L.; Xia, Z.; Wang, C.-Z.; Zhou, L.-D.; Zhang, Q.; Yuan, C.-S. J. Sep. Sci. 2018, 41 (15), 3060-3068 (Ref ${ }^{42}$ ) - Copyright 2018, with the permission from John Wiley and Sons.

To avoid the tedious centrifugation step after each step of the dSPE procedure, magnetic MIP particles can be prepared by various polymerization methods using different types of magnetic core (particles, nanotubes, nanosheet, porous structures...) as recently reviewed for MIPs developed for various types of molecules ${ }^{161}$ or only for biomacromolecules. ${ }^{152}$ In the most recent works involving MIP in dSPE, different types of magnetic sorbents were dispersed in the polymerization solution such as $\mathrm{Fe}_{3} \mathrm{O}_{4} \mathrm{NPs}^{34,98}$ silanized $\mathrm{Fe}_{3} \mathrm{O}_{4} \mathrm{NPs},{ }^{43,106,162,163}$ vinylized $\mathrm{Fe}_{3} \mathrm{O}_{4} \mathrm{NPs},{ }^{52,59}$ PEG-Fe $\mathrm{O}_{4}$ NPs, ${ }^{96}$ acrylic acid-, ${ }^{105}$ methacrylic acid-, ${ }^{164}$ boronic acid-, ${ }^{50,112}$ or oleic acid- $\mathrm{Fe}_{3} \mathrm{O}_{4} \mathrm{NPs},{ }^{165}$ and chitosan- $\mathrm{Fe}_{3} \mathrm{O}_{4}$ NPs. ${ }^{62}$ Microspheres of $\mathrm{Fe}_{3} \mathrm{O}_{4} \mathrm{NPs}$ covered by a layer of poly(GMA), ${ }^{102}$ microporous $\mathrm{SiO}_{2},{ }^{42,68,69,113,114,116,166-176}$ or $\mathrm{TiO}_{2}{ }^{111}$ were also recently reported. An example of particles produced using $\mathrm{Fe}_{3} \mathrm{O}_{4} @ \mathrm{SiO}_{2} \mathrm{NPs}$ as core particles is provided in Figure 7e. Among these studies, Li et al., who produced a layer of MIP by polycondensation of melamine, resorcinol, and formaldehyde in the pores of a mesoporous silica layer, used as sacrificial support, showed the effect of polymerization time on the adsorption capacity as well as on the selectivity of the MIP particles which reached an optimum after $3 \mathrm{~h} .{ }^{173}$

Other types of particles, such as silanized-hollow $\mathrm{Fe}_{3} \mathrm{O}_{4}$ microspheres, ${ }^{44}$ graphite flakes coated by $\mathrm{Fe}_{3} \mathrm{O}_{4} \mathrm{NPs}$ and further silanized, ${ }^{33} \mathrm{Fe}_{3} \mathrm{O}_{4}$ NPs covered by a mesoporous silica layer and further covered by $\mathrm{GO}^{177}$ or $\mathrm{GO}$ coated with $\mathrm{Fe}_{3} \mathrm{O}_{4} \mathrm{NPs}^{94}$ and further vinilyzed ${ }^{178}$ or covered by a mesoporous silica layer before being vinylized, ${ }^{179}$ graphene-CNTs grafted with $\mathrm{Fe}_{3} \mathrm{O}_{4} \mathrm{NPs},{ }^{180}$ 
CNTs covered by a $\mathrm{SiO}_{2}$ layer, ${ }^{118}$ silanized magnetic mesoporous carbon particles, ${ }^{181}$ cobaltbased magnetic nanoporous carbon prepared from MOF, ${ }^{182}$ and modified- $\beta$-cyclodextrin silanized $\mathrm{Fe}_{3} \mathrm{O}_{4} \mathrm{NPs}^{183}$ were also recently reported.

Magnetic properties were also obtained by the grafting of $\mathrm{Fe}_{3} \mathrm{O}_{4} \mathrm{NPS}$ at the end of the synthesis of the MIP previously prepared at the surface of mesoporous silica ${ }^{51}$ or by the in situ growth of $\mathrm{Fe}_{3} \mathrm{O}_{4} \mathrm{NPs}$ in the pores of the mesoporous imprinting silica prepared by a sol-gel approach with the presence of a surfactant. ${ }^{37}$ The introduction of silanized $\mathrm{Fe}_{3} \mathrm{O}_{4} \mathrm{NPs}$ in the polymerization mixture before bulk polymerization ${ }^{184}$ or by mixing $\mathrm{Fe}_{3} \mathrm{O}_{4} \mathrm{NPs}$ with the reagents used for precipitation polymerization ${ }^{185}$ was also proposed. The use of Janus silica nanosheets grafted with $\mathrm{Fe}_{3} \mathrm{O}_{4}$ NPs on one side and activated on the other side for the MIP coating by dispersion in the polymerization mixture ${ }^{153}$ or of silica nanobottles with a hydrophobic exterior surface used to produce a MIP layer and a hydrophilic internal surface functionalized by magnetic NPs were also reported. ${ }^{49}$ Some examples of magnetic particles prepared by some of these different approaches are reported on Figure 8.
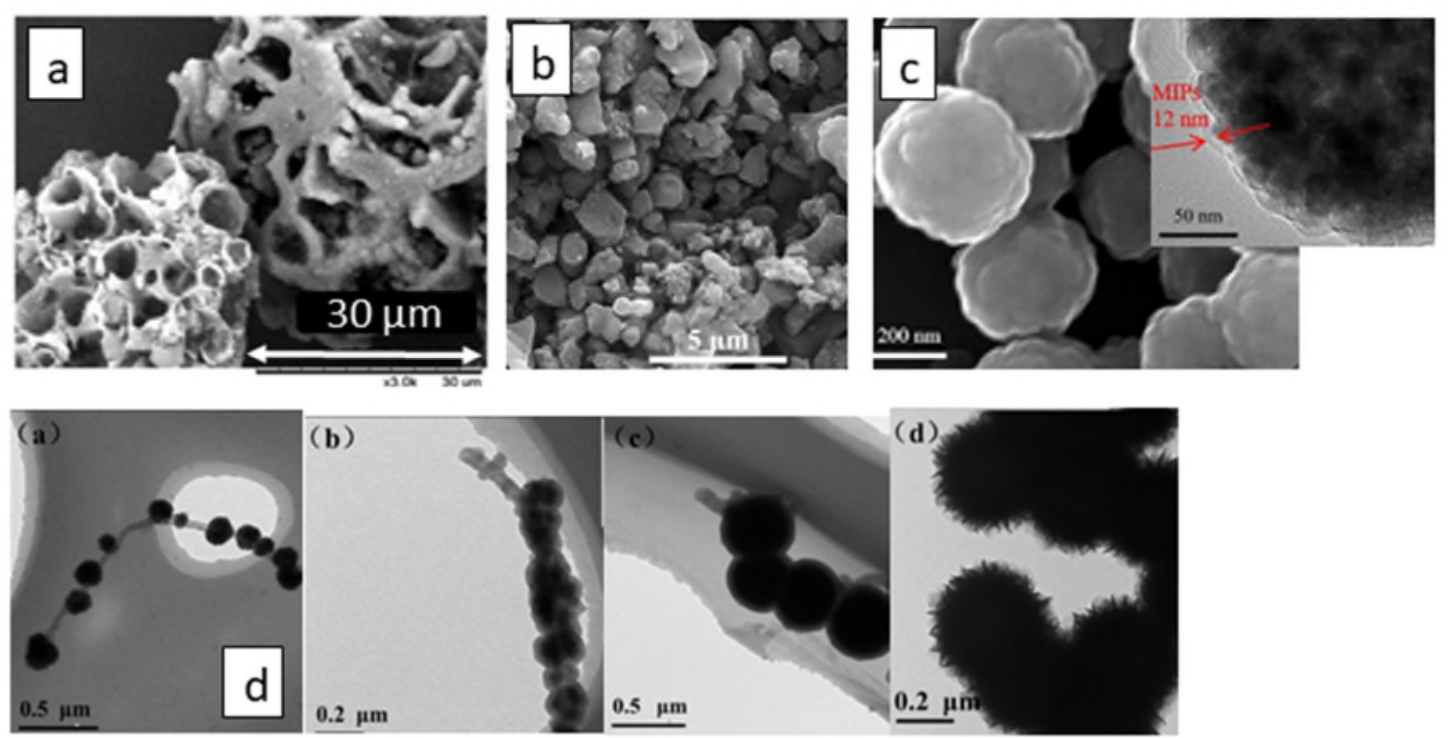

Figure 8: SEM images of (a) MIP prepared on silanized magnetic mesoporous carbon particles, (b) cobalt-based magnetic nanoporous carbon coated with MIP, (c) MIP prepared on the surface of hollow $\mathrm{Fe}_{3} \mathrm{O}_{4}$ microspheres (TEM picture in insert) and TEM pictures of CNTs (d-a), CNTs@SiO 2 (d-b), vinylized CNTs@SiO 2 (d-c) and CNTs@MIP (d-d). Part (a) (c) and (d) reproduced from Ge, Y.-H.; Shu, H.; Xu, X.-Y.; Guo, P.-Q.; Liu, R.-L.; Luo, Z.M.; Chang, C.; Fu, Q. Mater. Sci. Eng. C 2019, 97, 650-657 (Ref ${ }^{181}$ ) , Zhou, J.; Wang, Y.; Ma, Y.; Zhang, B.; Zhang, Q. Appl. Surf. Sci. 2019, 486, 265-273. (Ref ${ }^{44}$ ) and Qin, Y.-P.; Wang, H.-Y.; He, X.-W.; Li, W.-Y.; Zhang, Y.-K. Talanta 2018, 185, 620-627 (ref ${ }^{118}$ ) respectively - Copyright 2018 and 2019, with permission from Elsevier. Part (b) reproduced from Wu, C.; He, J.; Li, Y.; Chen, N.; Huang, Z.; You, L.; He, L.; Zhang, S. Microchim. Acta 2018,185 (11), 515. (Ref ${ }^{182}$ ) - Copyright 2018, with the permission from Springer Nature.

The objectives of these different approaches of synthesis are to obtain particles with a high specific surface area and a large amount of specific cavities while maintaining sufficient magnetic properties when magnets are used in the extraction procedure. Specific surface area 
values were measured by BET ( $\mathrm{N}_{2}$ adsorption) and were, for example, $243 \mathrm{~m}^{2} / \mathrm{g}$ for MIP developed on $\mathrm{SiO}_{2} \mathrm{NPs}^{115} 326 \mathrm{~m}^{2} / \mathrm{g}$ for 3D graphene-CNT hybrid composites ${ }^{180}$ or $320 \mathrm{~m}^{2} / \mathrm{g}$ for MIP particles obtained by bulk polymerization. ${ }^{143}$ To improve the surface area of dSPE-MIP particles, $\mathrm{SiO}_{2}$ nanospheres were coated by a covalent organic framework (COF) based on triformylbenzene and diaminobiphenyl as monomers and produced by heterogeneous nucleation and growth method. ${ }^{155}$ The improvement was demonstrated by the preparation in parallel of a COF-MIP by homogeneous nucleation, i.e. without the introduction of $\mathrm{SiO}_{2}$ nanospheres that led to a lower adsorption capacity, 152 instead of $322 \mathrm{~m}^{2} / \mathrm{g}$. In the same way, the use of a $2 \mathrm{D}$ boron nitride (BN) scaffold dispersed in the polymerization mixture in the presence of $\mathrm{Fe}_{3} \mathrm{O}_{4}$ NPs allowed to produce MIP NPs with a binding surface of 50 instead of 30 $\mathrm{m}^{2} / \mathrm{g}$ without the BN scaffold. ${ }^{107}$ Wang et al. recently compared different polymerization methods to produce a MIP for capsaicin such as bulk, precipitation polymerization, that give rise to non magnetic particles, and surface imprinting technology based on silanized $\mathrm{Fe}_{3} \mathrm{O}_{4}$ NPs, showing that the latest possess the best affinity and adsorption capacity. ${ }^{171}$ At last, to prepare a HRP-MIP, boronic acid was grafted on $\mathrm{Fe}_{3} \mathrm{O}_{4} \mathrm{NPs}$ covered by a porous $\mathrm{TiO}_{2}$ layer instead of a silica layer before the polymerization with dopamine in order to improve the specific surface area of the sorbent, since the surface of $\mathrm{Fe}_{3} \mathrm{O}_{4} @ \mathrm{TiO} 2$ is much rougher, which is beneficial to offer more binding sites. ${ }^{111}$

The measurement of the specific surface area is a parameter indicating the potential binding capacity of the MIP but it is also important to check for the presence of cavities. For this, as for other fields of application of MIPs, binding at equilibrium is studied on both MIP and NIP, and differences between MIP and NIP values indicate the presence of cavities. Those values are often given in $\mathrm{mg} / \mathrm{g}$ thus rendering difficult the comparison of MIPs specific of molecules of different sizes. Moreover, more than the capacity value itself, it is the ratio between the values obtained with the imprinted and non-imprinted supports, named the imprinting factor, which is important for assessing the presence of specific cavities. Recently, a careful optimization of several parameters affecting the binding properties of a glycoprotein on a MIP, prepared with boronic acid, by a comparison of the IFs obtained in various conditions of synthesis has been reported. ${ }^{66}$ An imprinted factor of 17.3 was obtained for the most promising sorbent for the target glycoprotein with IFs lower than 1.23 for 6 other proteins including glycoproteins, thus highlighting the very high selectivity of this MIP.

To improve the adsorption capacity while obtaining a high selectivity, different approaches were recently proposed. As an example, silica NPs were replaced by mesoporous silica NPs and by adding a surfactant in the sol-gel polymerization mixture thus improving the binding capacity of the MIP from 13.42 to $21.1 \mathrm{mg} / \mathrm{g}$, the imprinting factor being about $2.15 .{ }^{31} \mathrm{~A}$ high value of $108.1 \mathrm{mg} / \mathrm{g}$ was also reported for MIP particles for an acidic herbicide obtained by Pickering emulsion stabilized by a zeolith imidazolate framework, with only a value of 22.22 $\mathrm{mg} / \mathrm{g}$ for the NIP thus highlighting the imprinting effect. ${ }^{160}$ The use of metal chelation to immobilize the glycoprotein OVA onto NPs before initiating the surface imprinting in the presence of a boronic acid also led to a MIP having a higher adsorption capacity and selectivity that the MIP prepared with only boronic acid. ${ }^{71}$ 
At last, it is worthwhile to notice that the thickness of the MIP layer resulting from the different approaches described above to produce magnetic MIP particles is rarely given. If it affects the binding capacity, it also affects the final magnetic properties of the resulting particles. Indeed, for MIPs prepared on the surface of silanized $\mathrm{Fe}_{3} \mathrm{O}_{4} \mathrm{NPS}$, saturation magnetization values (SMVs) decrease only slightly in some cases, by a factor of 1.2 to $2,94,106,174,181$ but much more in other cases with losses by a factor of 3-5.3,113,114,168,169,185 7,167,179 and even 11.4. ${ }^{42}$ In one of these studies, the decrease by a factor of 5.3 was correlated to a too large thickness of the MIP layer (15 nm) covering NPs of $520 \mathrm{~nm} .{ }^{114}$ The SMV decrease was lower for a MIP layer on the surface of magnetic GO particles. ${ }^{94}$ Indeed, these particles of $16 \mathrm{~nm}$ gave rise to MIP particles of $40 \mathrm{~nm}$ (thickness of the layer about $12 \mathrm{~nm}$ ) causing only a decrease of the SMV by a factor of 1.7. The final SMVs belong to a wide range of values that have an impact on the time required to recover the particles with the magnet. Indeed, 5-30 s are required to recover particles with SMVs from 12.2 to 19.88 emu.g ${ }^{-1}, 33,62,113,114,163$ and 50-60 s with SMVs less than $5.33 \mathrm{emu} / \mathrm{g} .{ }^{37,42}$ It can be noticed that commercialized magnetic MIP particles have a low SMV of $1.52 \mathrm{emu} / \mathrm{g}{ }^{186}$

\section{Applications of MIP in dSPE}

MIP-dSPE was recently applied to the selective extraction, prior to their analysis, of biomarkers, ${ }^{50,51,149,153,174}$ glycoproteins, ${ }^{66,71,105,111}$ and drugs ${ }^{62,69,147,164,165,178,184}$ from biological fluids, proteins from blood or serum, ${ }^{35,106,114,118}$ from urine, ${ }^{64,113}$ or from cell culture, ${ }^{32}$ and of drugs from environmental waters, ${ }^{61,65,155,187}$ sediment ${ }^{175}$ or food. ${ }^{59}$ It was also applied to the extraction of natural products from plant extracts, ${ }^{42,45,46,107,108,169-171,177,188}$ foodstuff, ${ }^{58,146,148,154,163}$ bacteria extracts, ${ }^{48}$ human serum, ${ }^{173}$ waste, ${ }^{172}$ and environmental ${ }^{173}$ waters. Another application field is the monitoring of toxins or natural hormones in waters, ${ }^{94}$ food $^{117,168,182}$ and biological fluids. ${ }^{181}$ At last, recent works reported the use of dSPE-MIP for the extraction of pesticides from waters, ${ }^{160,167}$ soil, ${ }^{167}$ and food extracts, ${ }^{144,162,185}$ and of industrial pollutants from waters, ${ }^{31,33,37,47,158,166,179,183,186}$ food, $^{34,68,96,98,180,183}$ or samples collected in an industrial bioreactor. ${ }^{53}$

Another objective of sample purification using MIP is the removal of a class of compounds that interfere with the analysis of the target analytes. For example, MIP particles prepared using $\beta$ carotene were used to remove this molecule and other carotenoids from food, in replacement of conventional SPE sorbent in QuECheERS procedure, to improve the reliability of the analysis of pesticides in this sample, showing a limited loss of the pesticides compared to conventional sorbents. ${ }^{146}$ It is interesting to note that if in some cases a MIP can trap several analogs of the template molecule, it is not always the case. As an example, a MIP developed for the selective trapping of microcystin-LR using this target molecule as template has shown to be very specific to this microcystin, which is a very different behavior from that of antibodies able to recognize and then trap several structural analogues. ${ }^{94}$

In most of the cases, 5-100 mg of particles are dispersed in the samples. The ratio between the amount of MIP particles and the volume of the sample, that has only been optimized in some cases, ${ }^{68,180}$ can be lower than $1,^{32,33,44,94,143,158,169,179}$ between 1 and 10 , 
$34,66,69,144,149,168,174,181,188$ and even $250 \mathrm{mg} / \mathrm{mL}^{43}$

Environmental waters were filtered ${ }^{172}$ or directly put in contact with the MIP particles for the extraction of target analytes. A direct extraction was also applied to an apple juice. ${ }^{173}$ However, viscous liquid samples such as honey, milk, juice, or olive oil were diluted in a buffer ${ }^{50,148,185}$ or in a solvent. ${ }^{144}$ Wine samples were first treated by LLE to remove some interfering compounds. 154 Urine samples were extracted without any treatment, ${ }^{113,164,173}$ or after $\mathrm{pH}$ adjustment, ${ }^{165}$ filtration, ${ }^{174}$ centrifugation, ${ }^{147}$ dilution by a factor of $25,{ }^{153}$ or a complex sample pretreatment involving a dilution with a buffer $(1: 1, \mathrm{v} / \mathrm{v})$ and a first SPE extraction step on C18 silica. ${ }^{149}$ For serum samples, a direct extraction, ${ }^{173}$ a dilution by a factor $50,{ }^{111} 100,{ }^{105,106} 150,{ }^{114} 200^{118}$ or $250,{ }^{66}$ or a protein precipitation step ${ }^{69}$ that can be followed by a dilution with a buffer was

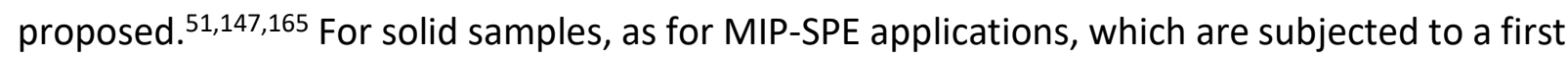
treatment with a solvent, the resulting liquid extracts are put in contact with MIP particles either directly ${ }^{117}$ or after a dilution with a buffer or a hydro-organic mixture. ${ }^{34,59,96,180,182,185}$ While all these sample pretreatment procedures are varied and aim to make the sample less viscous or to eliminate certain interfering compounds such as proteins, the conditions are rarely, if ever, really justified.

The desorption of small molecules is mainly achieved using organic solvents that may contain some acids to help desorption. The addition of DES in methanol to desorb a nephrotoxin was also recently reported. ${ }^{181}$ Concerning large molecules, some works described the desorption of glycoproteins from boronate-MIP with $5 \%$ acetic acid combined with up to $30 \%$ acetonitrile in water ${ }^{111}$ or a solution with a high salt content. ${ }^{64}$ For thermo-sensitive MIPs, this solution with a high salt content was combined with a decrease in the temperature from 32 and 35 to 20 and $25^{\circ} \mathrm{C}$ for $\mathrm{BSA}^{44}$ and some alkaloids, ${ }^{45}$ respectively. Desorption of protein was also ensured by the use of a surfactant combined with acetic acid ${ }^{118}$ or with UV irradiation for a MIP prepared with photo-switchable monomers, ${ }^{114}$ but only a partial release was reported in this last case. Irradiation at two different wavelengths was also applied to a photo-responsive MIP prepared for cyclodextrine. ${ }^{41}$

\section{Optimization of the dSPE procedure}

A dSPE is based on an equilibrium during the extraction but also during the desorption step and this procedure can be achieved with an extraction time that can be close to those of the SPE-MIP method, from 10 to 30 min. ${ }^{32,107,111,155,167,168,179,180,182,183}$ However, many studies reported very long durations, up to $1 h h^{33,34,51,69,94,98,102,163,177,181} 2 h^{44,50,61,149,170}$ or even more. ${ }^{35,41,43,45,65,106,172}$ These long times concern in some cases the extraction of macromolecules that have low molecular diffusion coefficients or the use of thermo- or photoresponsive MIPs whose structural modifications require longer times. It is also interesting to note that in some studies the duration of the extraction and desorption steps was not optimized. Some authors also reported the use of ultrasound to shorten the dSPE duration time. ${ }^{147,155,156,165,174}$ 
The optimization of the extraction conditions with real samples is very rarely described. In most of the cases, it is worthwhile to notice that the optimization was achieved by studying the binding of the target molecule(s) in pure media, in very few cases with also a comparison with the NIP, and then the optimal conditions were applied for real samples without any additional study of matrix effects. However, Gast et al. recently reported that this MIP/NIP comparison can be helpful for optimizing the selectivity in real samples. Indeed, they studied the effect of the dilution rate of cell culture supernatant on the fixed amount of a viral hexon protein, showing that the dilution improved the selectivity of the trapping by decreasing the amount retained by the NIP. ${ }^{32}$

As with conventional dSPE sorbents, the key-parameters to be optimized are the sample volume, the ratio of the sample volume and the amount of sorbent, the extraction time, the agitation rate, the $\mathrm{pH}$ of the sample, the nature of the solvent, and the time required for desorption. ${ }^{189}$ In MIP-dSPE, a washing step was in some cases introduced before desorption to remove some interfering compounds, ${ }^{50,62,162,164,165,170,173}$ but no real optimization of this step was reported. Some other parameters can also be studied such as the number of extraction or desorption steps or the use of shaking devices (rotary shaker, ultrasonic bath). When their optimization was done, it focused only on finding the conditions leading to the highest extraction recoveries, but without verifying the binding on the NIP that should be as low as possible to ensure an optimal selectivity of the extraction process. Indeed, there are only a few cases studying the effect of the polymer amount, ${ }^{50,185}$ loading time ${ }^{117,184}$ and volume, nature, 68 and $\mathrm{pH}$ of the sample $\mathrm{e}^{50,113,185}$ on the binding on both MIP and NIP to find conditions giving rise to the best selectivity.

Most of the authors, who reported some optimization of extraction conditions, used a onevariable-at-a-time approach, while keeping the others fixed. They mainly studied the effect of $\mathrm{pH}^{98}$ time of extraction and desorption ${ }^{68,98,180}$, and nature ${ }^{180}$ and volume of the desorption solution $33,65,94,149,155,165,174,177,181$ on the binding properties. The major drawback of this approach is that it cannot completely consider the collaboration effects among the factors and subsequently is incapable of attaining the true optimum level, i.e. the optimal extraction recoveries on MIP. To overcome this drawback, an experimental design can be used to first identify the main influencing factors. This was done for example with a Plackett-Burman approach and considering the NIP and MIP as a "polymer type" factor to evaluate the impact of the imprint on the results. ${ }^{186} \mathrm{~A}$ box-Behnken design was also applied to optimize the elution conditions (frequency, time, and volume) of carbamazepine. ${ }^{62} \mathrm{~A}$ central composite design (CCD) with four parameters, selected after having set some other parameters, and a response surface methodology (RSM) or, in case of multi-criteria optimization, a desirability function were also employed to help optimize the dSPE conditions. ${ }^{96,147,169,178}$

\section{Evaluation of the dSPE performances}

In most of the reported studies, EFs are very low, even lower than 1, the objective being more the purification than the concentration of the analytes. An example of purification effect is given by the comparison of chromatograms provided in Figure 9 that corresponds to the 
analysis of grape (Figure 9a) and apple (Figure 9 b) juices before (black) and after the desorption of MIP (red) or NIP (blue) particles dispersed in the same samples. ${ }^{173}$ The complexity of these juices is demonstrated by their direct LC-UV analysis with coelution of GA with some interferences. The use of MIP-dSPE allows the selective extraction of GA, no interferences being observed, whereas no GA peak was observed in the elution fraction from the NIP thus highlighting the contribution of the MIP cavities in the extraction process.
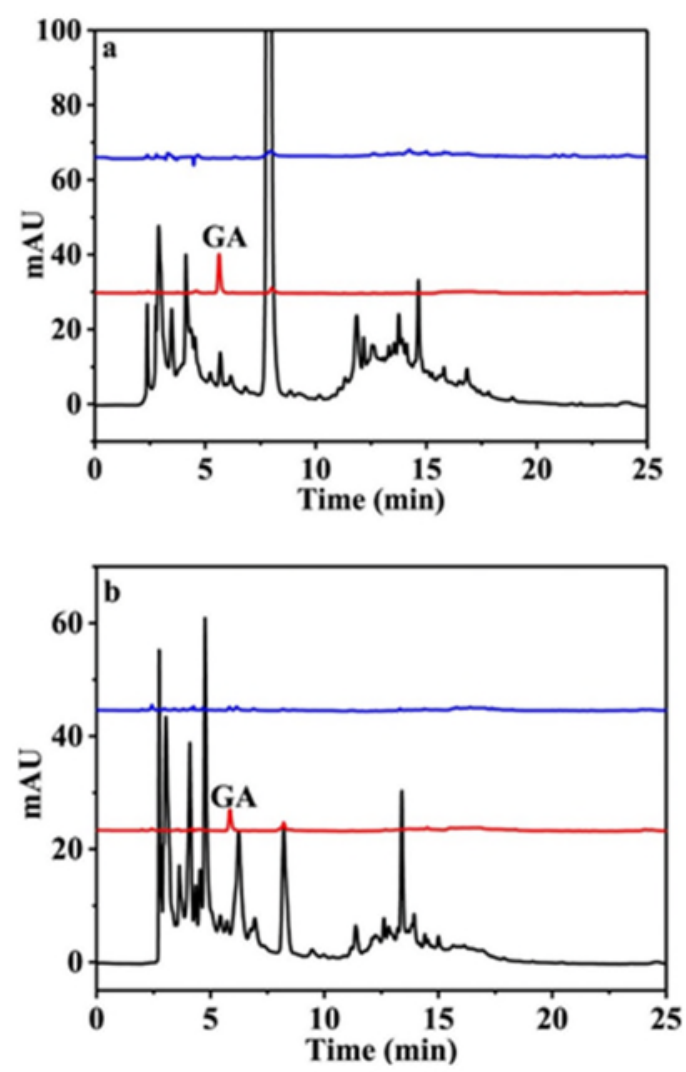

Figure 9: Chromatograms corresponding to the analysis of gallic acid (GA) in grape juice (a) and apple juice (b) (black line), and of the desorption fraction after dSPE on MIP (red line) and on NIP (blue line). Reproduced from Li, H.; Long, R.; Tong, C.; Li, T.; Liu, Y.; Shi, S. Talanta 2019, 194, 969-976 (Ref ${ }^{173}$ ) - Copyright 2019, with the permission from Elsevier.

Nevertheless, EFs of $20^{170}$ and even 60-75 without evaporation for urine samples or food extracts, ${ }^{147,169}$ and higher than 150 after an evaporation of the desorption solution to concentrate it were obtained. ${ }^{34,96,178}$ If most of the studies concern the trapping of a target molecule and one or two analogs in some cases, Li et al. reported EFs from 16 to 20 for 6 NSAIDs in waste water with IFs between 2 and 2.3 using ibuprofen as template. ${ }^{155}$

As for SPE-MIP, the validation of a dSPE procedure was mainly based on the intra- and interday studies of the extraction recoveries, measured mainly in pure media $59,96,180,184$ but also in real samples, in their native form ${ }^{62,181}$ or spiked at different concentration levels. $37,45,50,51,62,65,69,94,96,113,149,163,165,168,172,174,178,183,184$ 
Li et al. compared MIP and C18 silica particles to evaluate their difference in term of adsorption capacity of drugs from environmental waters, that was higher with the MIP (factor 2.6). ${ }^{155} \mathrm{~A}$ similar comparison was reported by Lu et al. that observed a higher selectivity, with a better clean-up effect with the MIP. ${ }^{167}$ Liang et al. also compared the binding of a natural product on MIP and NIP particles immersed in real samples showing an extraction capacity of the MIP 2.5 higher than that of the NIP, thus illustrating the contribution of specific cavities in real conditions, even in the presence of a large amount of interfering compounds. ${ }^{188}$ Similar conclusions were obtained by $\mathrm{Ge}$ et al. as a higher binding capacity was obtained in urine samples with the MIP particles than with other sorbents such as NIP but also magnetic mesoporous carbon particles (used as core for the production of the MIP particles), or bare silica and C18 silica particles. The lower binding on NIP showed again the contribution of the specific cavities for the binding of the target in real samples. ${ }^{181}$

The matrix effect in the HPLC-UV analysis of carbamazepine in urine and serum was evaluated and matrix effect factors ranged from 88.14 to $97.45 \%$ with SD within $7.59 \%$ thanks to the MIP clean-up. ${ }^{62}$ Similar results were obtained for the extraction of 6-mercaptopurine from human plasma and its analysis by LC-MS, ${ }^{69}$ perphenazine from non treated urine and its analysis by HPLC or HPTLC, ${ }^{164}$ and folic acid from lettuce and cookies and its analysis by LC-MS. ${ }^{58}$ As already reported for MIP-SPE, thanks to the clean-up effect brought by the MIP, chromatographic methods typically used to analyze the dSPE extract can be replaced by a direct analysis by IMS as it was done for example for cocaine in saliva, which is a faster but also greener method compared to LC-MS often used for this application. ${ }^{184}$

The study of the reusability of the dSPE particles was often reported. The possibility to use them in $3,53,105,185 \quad 5,{ }^{31,45,46,50,62,96,117,153,154,175,179,188} \quad 6,^{43,94,94,111,113,167,172,182} \quad 7,49,115 \quad 8$, $37,44,102,159,1809,15610,35,47,163,17020^{178}$ and even $30^{155}$ cycles, was mainly studied in pure media and resulted in a difference in binding efficiency between 3 and $15 \%$ between the first and the last use. A loss of capacity efficiency of $15 \%$ after the treatment by dSPE of four urine sample extracts was also reported. ${ }^{149}$

Concerning the MIP particles produced by bulk (by introducing silanized $\mathrm{Fe}_{3} \mathrm{O}_{4}$ NPs in the polymerization mixture), their non-reusability was mentioned, but a good repeatability of their synthesis, which favors their single use, was reported. ${ }^{184}$ It is interesting to note that the repeatability of the synthesis is very rarely studied, leading authors to often characterize their media with great precision and to evaluate the performance of their methods without verifying that the synthesis of these media is repeatable. However, two ${ }^{162}$ or five $\mathrm{for}^{5013}$ independent synthesis of magnetic MIP particles led to RSD values lower than $6 \%$ for adsorption capacity. ${ }^{50}$ In addition, highly reproducible recoveries of sialic acid in pure samples were obtained using a hollow magnetic MIP, with RSD values of 1.6 and $5.5 \%$ for intra- and inter-batch measurements, respectively. ${ }^{51}$ At last, Wang et al. compared the binding properties of MIPs obtained with three independent syntheses and they were very close, this study being also achieved on the corresponding NIP in order to also check the repeatability of the selectivity. ${ }^{46}$ 


\section{MIP in SPME and related techniques}

Other methods based on the partition equilibrium of the target between the sample and MIP were developed by replacing particles by other formats such as fibers or rods of different sizes, resulting in selective extraction methods named solid-phase microextraction (SPME) and stirbar sorptive extraction (SBSE). Mostly developed for the extraction of the volatile compounds before their analysis by GC after their thermodesorption, the application of SPME has been extended to biological fluids with an off-line coupling with LC. In this case, the desorption is achieved with a solvent, which no longer requires the use of sorbents stable at high temperature.

SPME generally consists in the extraction of compounds by immersing a fused silica fiber (100 $\mu \mathrm{m}$ diameter) usually coated with polydimethysiloxane (PDMS), divinylbenzene (DVB), polyacrylate (PA) or a combination of them, into a sample. As recently reviewed, numerous groups work on the replacement of conventional coating material to improve its potential to a larger range of compounds, ${ }^{190}$ recent reviews focusing particularly on the use of MIPs as coating material. ${ }^{120,191}$ This part of the review summarized the last developments in this field.

\section{Preparation of the MIP fibers}

Among the different approaches allowing the preparation of MIP-fibers recently reviewed, ${ }^{120,191}$ recent works have shown that MIP fibers can be prepared by coating a stainless steel fiber $(6 \mathrm{~cm} \times 200 \mu \mathrm{m} \text { diameter })^{192}$ or a silica glass fiber $(1.8 \mathrm{~cm} \times 300 \mu \mathrm{m}$ diameter) ${ }^{79}$ by immersing them in a $1 \mathrm{~mm}$ diameter glass capillary filled will the polymerization solution. The capillary acts as a mold to form the MIP layer around the fiber. Another approach involved a pre-activation step of a stainless steel fiber by dipping it in an acidic solution before its immersion for a controlled time in a polymerization solution to coat it with a MIP layer, the immersion being achieved three times to ensure a sufficient coating of the fiber. ${ }^{193}$ A MIP fiber can also be in situ synthesized in a capillary filled with the polymerization solution and acting as a mold. In this case, the capillary size defines the fiber size and fibers of $2.5-2 \mathrm{~cm} \times 530 \mu \mathrm{m}$ diameter ${ }^{76,80}$ or $4 \mathrm{~cm} \times 300 \mu \mathrm{m}$ diameter ${ }^{194}$ were synthesized. A larger mold, $3 \mathrm{~cm} \times 3.5 \mathrm{~mm}$ diameter, was used to prepare four fibers then tied up together to form a fiber bundle. ${ }^{85}$

\section{Optimization of SPME procedures and applications}

MIP-SPME was applied to the extraction of pollutants from waters, ${ }^{79}$ of drugs from diluted biological fluids ${ }^{76}$ or food extracts, ${ }^{85}$ of pesticides from juices after their filtration and their dilution in water 80,194 and of flavonoids from green tea or coffee. ${ }^{193}$ A MIP fiber was also applied to in vivo sampling of a flavonone and its metabolites for uptake studies from a liver of an anesthetized rat. ${ }^{192}$ It is interesting to note that to improve the selectivity of the MIPSPME procedure when it is used with biological samples, BSA was coated the surface of the MIP after its preparation to limit the extraction of macromolecules from biological samples during the extraction of the targets. ${ }^{76,192}$ 
As for conventional sorbents, the extraction efficiency of the MIP-SPME device depends on different parameters such as the sample nature, the amount of extraction sorbent, the extraction time, the stirring rate, and the extraction temperature. Due to the instability of MIPs at high temperatures, desorption is achieved by immersing the fiber in a solvent, which also involves optimizing its nature and volume, and desorption time. The optimization of these parameters was mainly achieved by studying the amount of target molecule fixed on the MIP fiber, but without studying the NIP that is only used as control after this optimization with the exception of only two cases where the MIP/NIP comparison was achieved to set the extraction time. ${ }^{80,192}$ As for d-SPE, experimental designs can help optimize these numerous parameters. For example, a Box-Behnken design (BBD) with 3 variables and RSM allowed to optimize six parameters affecting the extraction (sample $\mathrm{pH}$, amount of salt in the sample, and duration) and desorption (nature and volume of the solvent and duration) steps. ${ }^{85}$ As dSPE, the MIPSPME method is based on a partition equilibrium during the extraction but also the desorption step. Therefore, this procedure is quite long compared to SPE and requires from $50 \mathrm{~min}-1 \mathrm{~h}$ $85,193,194$ up to $2 \mathrm{~h} .{ }^{79}$

\section{Evaluation of the SPME performances}

The reproducibility of the fiber preparation was evaluated for the GO/MOF/MIP fiber, showing RSD values on the extracted amount of 3.4-4.1\% for consecutive extractions on one fiber and of $4.3-5.2 \%$ for five similarly prepared fibers. ${ }^{85}$ These values are very satisfactory and only slightly higher(difference of $1 \%$ ) than for a MIP prepared by the same group without adding GO/MOF nanocomposite in the polymerization solution. ${ }^{194}$

If MIP-SPME was mainly applied to the selective extraction of target molecules from samples without any focus on the concentration effects, large enrichment factors were reported for some applications. Indeed, EFs of 200 and about 440 for an initial volume of $20 \mathrm{~mL}$ of diluted food extracts ${ }^{80}$ or $4 \mathrm{~mL}$ of waters (including a concentration step of the desorption solution by evaporation $)^{85}$ were reported, respectively.

The potential of the MIP-SPME fibers was studied by comparing their efficiency to extract target analytes with fibers based on $\mathrm{PA}^{79}{ }^{79} \mathrm{DVB}^{192}$ and PDMS. ${ }^{79,192}$ In all cases, higher extraction efficiencies were obtained with the MIP-SPME fibers. However, it should not be forgotten that the amount of extracted analyte is proportional to the amount of extracting phase and that the MIP fibers have larger dimensions than those commercialized, that are coated with no more than $0.5 \mu \mathrm{l}$ of polymer. At last, as for the previous extraction techniques, the selectivity brought by the MIP was exploited to facilitate the direct analysis of the extract by IMS. ${ }^{194}$ When the reusability of the fiber was studied, it was high, with up to $25^{193}$ or 100 cycles. ${ }^{79}$

To improve the extraction efficiency and stability of a MIP-fiber, the fiber was prepared by dispersing a nanocomposite of GO and of metal-organic framework (MOF, ZIF-8) in the polymerization solution. ${ }^{85}$ At last, a polymerizable $\beta$-cyclodextrin was used as monomer to form a so-called supramolecularly imprinted polymeric SPME coating for the extraction of phenols, including bisphenol A, from waters leading to a higher binding capacity than the MIP 
prepared with the conventional MAA monomer. ${ }^{79}$ This MIP was also selective as IFs between 1.4 and 2.3 depending on the target molecules were measured using a $\beta$-cyclodextrin basedNIP. Unfortunately, the IF values with the MAA-NIP were not provided, which prevents the evaluation of the selectivity contribution of the $\beta$-cyclodextrin-based approach compared to the single use of MAA.

\section{SBSE and related techniques}

Recently the inner and outer surfaces of a silica capillary (15 $\times 1 \mathrm{~mm}$ ) was immersed in a polymerization solution leading to a capillary both filled and coated with a MIP, thus increasing its binding capacity compared to the previously described MIP-SPME devices. ${ }^{84}$ This in- and out-tube coating-SPME device was applied to the extraction of endocrine disrupting chemicals from waters in less than $30 \mathrm{~min}$. The reproducibility of the binding amount of one fiber is 2.46.6\% (RSD, $n=5$ ) and fiber-to-fiber is $4.5-8.1 \%$ (RSD, $n=5$ ) and authors did not observed a significant change in the binding properties over 100 cycles, which indicates an excellent stability and reusability of this coating approach.

If the objective of this work was to increase the amount of MIP sorbent by filling the capillary inside, the same objective motivated other groups to developed MIP-SBSE type devices, as for conventional SBSE devices whose potential has been recently reviewed. ${ }^{195}$ For this an iron bar ( $15 \times 2 \mathrm{~mm}$ diameter) was activated in surface and immersed in the polymerization mixture. ${ }^{78}$ Despite the good performances obtained for the extraction of naphthalene sulfonates from sea waters in terms of recoveries, selectivity, and reusability (50 cycles), no data related to the dimension of the layer were provided. In the same way, a sealed glass tube containing an iron wire $(30 \times 5 \mathrm{~mm}$ ) was introduced in a second glass tube containing $3 \mathrm{~mL}$ of the polymerization mixture ${ }^{196}$ In this case, the resulting MIP layer thickness was estimated to $1.41 \mu \mathrm{m}$. Extraction recoveries higher than $80 \%$ with variations of $4.11 \%$ (RSD, $n=5)$ from batch-to-batch indicate a good efficiency and reproducibility of the preparation procedure. This device was applied to the extraction of semicarbazide from fish samples. A similar approach was used by introducing a sealed glass tube $(20 \times 2 \mathrm{~mm})$ containing a $16 \mathrm{~mm}$ iron rod in $0.4 \mathrm{~mL}$ of the polymerization mixture to prepare a MIP stir bar for the extraction of six $\beta$-agonists from food extracts previously treated by TCA and LLE. ${ }^{77}$ This MIP-stir bar was reused more than 60 times and was very selective towards the target compounds giving rise to higher recoveries on the MIP (40$90 \%)$ than on the NIP (<20\%) in 70 min.

In a recent work, Alvani-Alamdari et al. compared a MIP-dSPE procedure with a MIP-SBSE procedure for the extraction of carbamazepine from precipitated serum. ${ }^{176}$ The MIP-SBSE was prepared by introducing a $30 \mathrm{~mm}$ magnetic core coated with glass in the polymerization solution. The same polymerization mixture was used to immerse $\mathrm{Fe}_{3} \mathrm{O}_{4} @ \mathrm{SiO}_{2} \mathrm{NPs}$ to prepare MIP-dSPE particles. The MIP-stir bar (MIP amount not mentioned) or $40 \mathrm{mg}$ (optimized amount) of magnetic MIP NPs were immersed during $15 \mathrm{~min}$ in a $500 \mu \mathrm{L}$ plasma sample (after a precipitation step) and desorbed for $20 \mathrm{~min}$. A better sensitivity was obtained in dSPE, since NPs have a higher surface-to-volume ratio. 
A stir bar was also prepared by introducing magnetic NPs as magnetic cores in a glass insert ( 3 $\mathrm{cm} \times 4.5 \mathrm{~mm}$ ) containing the polymerization mixture (35 mg NPs in $0.5 \mathrm{~mL}$ of the polymerization mixture) and used as a mold. ${ }^{197}$ After its removal from the glass insert, a thin PTFE strip was wrapped around the middle of the stir bar to ensure a correct rotation under stirring. This MIP-SBSE device was used for the extraction of fungicides from orange extracts. An EF of about 16 was obtained after 50 min of treatment that included a 10 min washing step to remove the interfering compounds, thus providing a high degree of clean up.

To prepare a larger device, the in situ bulk polymerization of a MIP at the surface of a vinylizedPTFE membrane (with a $25.3 \mathrm{~mm}$ diameter using $1 \mathrm{~mL}$ of polymerization mixture) placed between two magnet rings was recently proposed. ${ }^{187}$ This MIP-disk was then immersed during $30 \mathrm{~min}$ in a $200 \mathrm{~mL}$ water sample for the selective extraction of a cocaine metabolite. After washing with $50 \mathrm{~mL}$ of water, the desorption was achieved in 30 min with $5 \mathrm{~mL}$ of acidified methanol further analyzed by IMS.

In contrast to the increase in the dimensions of the extraction devices generally sought by moving from SPME to SBSE, the development of MIP nanofibers has been recently proposed. Indeed, MIP nanofibers were successfully fabricated by electrospinning while introducing Nylon 6 in the sol-gel polymerization mixture. Fibers with diameters in the 80-145 nm range were obtained and applied to the extraction of bisphenol A from pure aqueous media. ${ }^{100} \mathrm{~A}$ binding capacity of $103.8 \mathrm{mg} / \mathrm{g}$ was obtained, the selectivity being proven with recoveries on MIP and NIP of $83.5 \%$ and $36.8 \%$, respectively.

\section{Extraction devices combining MIP with membranes or plates}

\section{Dispersive extraction on membranes or plates}

Other formats complementary to particles, fibers, stir bars or magnetic disks previously described, have been proposed to carry out extraction under equilibrium. As an example, a membrane was prepared using MIP particles $\left(15 \mathrm{mg}\right.$ ) and agarose. ${ }^{198}$ The resulting membrane ( $1 \times 10 \mathrm{~mm}$ diameter) was placed into a $12.5 \mathrm{~mL}$ sample for the extraction of sulfonamides from waters. A small volume of $250 \mu \mathrm{L}$ was sufficient for the desorption and EFs higher than 20 were reported. Agarose was also involved in another reported work related to the use of a fiber glass paper (disk of $0.5 \times 6 \mathrm{~mm}$ diameter) put in contact with MIP particles and agarose and the resulting MIP-disk was introduced in $250 \mu \mathrm{L}$ urine for $2 \mathrm{~h}$ for the extraction of cotinine. ${ }^{199}$ MIPs were also recently produced at the surface of polyethylene filter plates (no data provided related to their size) previously treated by multi-walled CNTs. ${ }^{36}$ Four plates were mixed with $5 \mathrm{~mL}$ cosmetic product extracts for the selective extraction of prednisone in just over $2.5 \mathrm{~h}$.

A RAFT polymerization method, often chosen to control the thickness of the MIP layer, was selected for the synthesis of a MIP at the surface of hydroxylated-PDMS plates $(1 \times 1 \mathrm{~mm})$ and $10 \mathrm{mg}$ of these MIP-PDMS plates were mixed with $5 \mathrm{~mL}$ orange juice for $60 \mathrm{~min}$ for the selective extraction of folic acid. ${ }^{200}$ Another way to prepare such a membrane consisted in 
applying the polymerization mixture to a $1.26 \mathrm{~cm}$ diameter paper. Three repetitive deposits (with drying step between the deposits) were required to obtain a sufficient MIP thickness. This device was immersed in a soda drink for the selective extraction of quinine. ${ }^{99}$ Imprinted membranes of $40 \mu \mathrm{m}$-thickness were prepared by the cross-linkage of chitosan around methylparaben (MP) used as template on the top of a glass plate. ${ }^{97}$ These membranes were involved in a matrix solid phase dispersion procedure: $150 \mathrm{mg}$ of MIP-membranes were mixed with $50 \mathrm{mg}$ of powder sunscreen sample and sea sand. The mixture was further introduced in polypropylene cartridge between frits and a washing step with hexane was applied before the elution of MP by acidified methanol. No data related to the reproducibility of the synthesis of these different devices were reported.

\section{Membrane protected solid-phase extraction}

Recently, MIP spherical particles prepared by emulsion polymerization were encapsulated in a polypropylene (PP) porous membrane for the direct extraction of triazines from tea extracts. ${ }^{150}$ The amount of MIP introduced in the membrane and the size and number of membranes used for one extraction were optimized by a Box-behnken design. Three bags of $1.5 \times 1.5 \mathrm{~cm}$ containing each $50 \mathrm{mg}$ of MIP particles allowed the extraction of triazines in 35 min from a hexane extract of tea $(10 \mathrm{~mL})$. This method was compared to a conventional SPE procedure with $\mathrm{C} 18$ silica showing the higher efficiency of the MIP-bag approach to limit matrix effects. A similar approach using a smaller amount of MIP, $50 \mathrm{mg}$ of MIP introduced in a unique cone-shaped PP membrane, was applied to the extraction of cathinones from $1 \mathrm{~mL}$ urine in 4 min. ${ }^{201}$ This device was used 27 times without observing loss in recoveries. At last, $10 \mathrm{mg}$ of MIP particles were packed in a dialysis bag $(21 \times 15 \mathrm{~mm})$ to extract luteolin from bacteria extracts in $200 \mathrm{~min}$, the bags being reusable for 5 extraction cycles. ${ }^{48}$ No data related to the reproducibility of the synthesis of these different devices were reported.

\section{Concentration of target by deposition on membrane/plate surface}

MIP-membranes were also produced to selectively concentrate target analytes on their surface. For example, metalloproteins (MPs) were selectively concentrated from plasma sample deposited on the surface of a MIP-MALDI plate, prepared by polycondensation of dopamine in the presence of an MP on the plate. ${ }^{95}$ After $1 \mathrm{~h}$ of extraction (contact time) and three washing steps, the MPs were analyzed by MALDI-TOF-MS. This procedure is summarized on Figure 10.

A strong enhancement of their MS signal and a low intensity of the albumin peak was reported thus demonstrating the selectivity of the concentration process that took place on the plate. A MIP for a glycopeptide antibiotic was also recently prepared in the pores of a microporous membrane of polyvinyldene fluoride $(2.5 \times 3 \mathrm{~cm})$ and applied to the extraction of this target from fetal bovin serum. ${ }^{202}$ After $2 \mathrm{~h}$ of extraction (contact time) and a washing step, the glycopeptide was recovered in $5 \mathrm{~mL}$ of methanol further analyzed by UV. Some matrix effects being observed, a protein precipitation step was first applied to the sample thus allowing to 
obtain accurate results. Again, no data related to the reproducibility of the synthesis of these devices were reported.

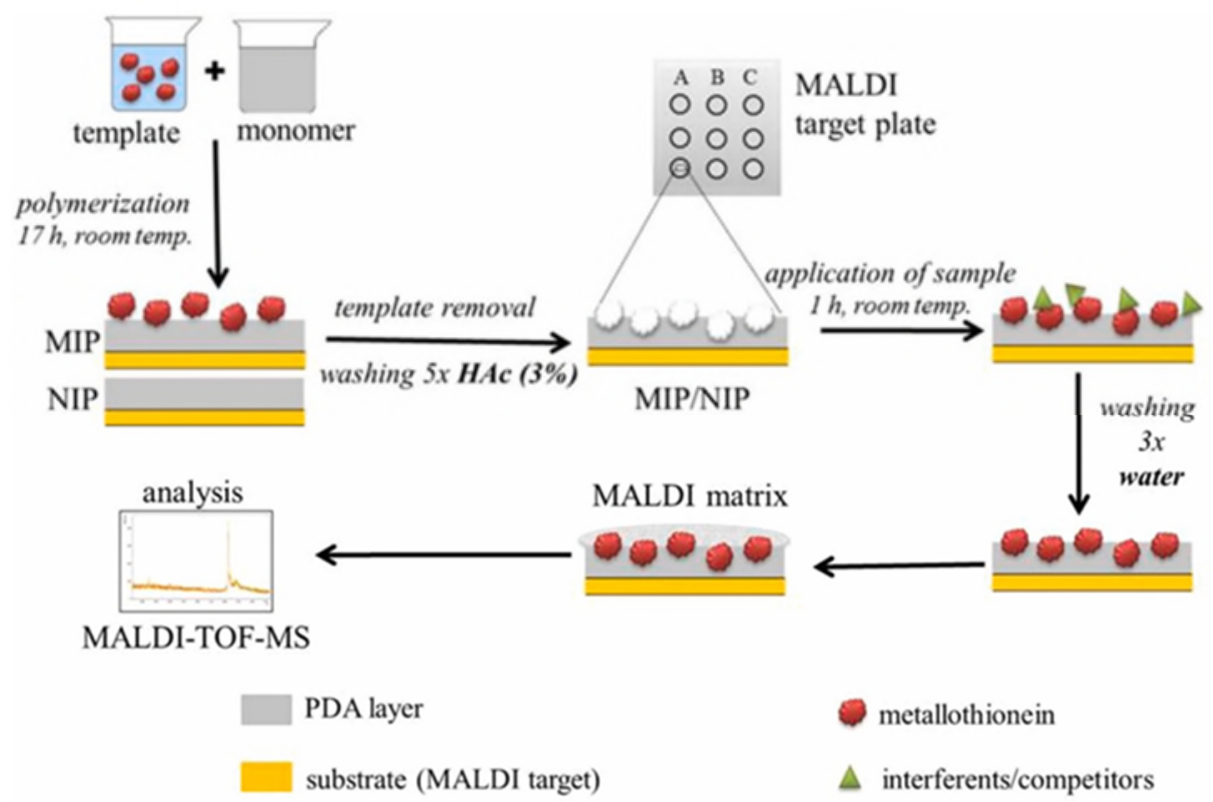

Figure 10: Overall workflow of MIP formation, sampling and MALDI-MS detection of an MP, metallothionein. Reproduced from Vaneckova, T.; Vanickova, L.; Tvrdonova, M.; Pomorski, A.; Krężel, A.; Vaculovic, T.; Kanicky, V.; Vaculovicova, M.; Adam, V. Talanta 2019, 198, 224-229 (Ref ${ }^{95}$ ) - Copyright 2019, with the permission from Elsevier.

\section{Conclusion}

Throughout the review, we highlighted the diversity of approaches leading to the preparation of MIPs as selective extraction media for targeted molecules from complex samples. These sorbents have proved their worth for the selective trapping of molecules with very varied physico-chemical properties. Recent results obtained for proteins, targets that are currently particularly studied, suggest that they will in the near future be an alternative to antibodies that are still widely used in the clinical field.

Significant progress has been made by the authors in validating these materials for use in real samples, although it appears that it is still necessary to continue studies on the validation of synthesis, with little works highlighting this aspect.

Particular emphasis was also placed on so-called green synthesis to limit the consumption of toxic reagents, as well as on the removal of conventional chromatographic methods, since the removal by the MIP of interfering compounds from the extracts allows the direct detection of the target analyte in the extract by detection methods such as direct UV detection and MS without observing matrix effects. 


\section{Author informations}

\section{Corresponding Author}

Valérie Pichon; email : valerie.pichon@espci.fr , Tel: +33 140794 772, Fax: +33 140794 776. LSABM, ESPCI Paris, 10 rue Vauquelin, 75005 Paris, France

\section{ORCID}

Valérie Pichon N: 0000-0002-9232-2861

\section{Author Contributions}

The manuscript was written through contributions of all authors. All authors have given approval to the final version of the manuscript.

\section{Notes}

The authors declare no competing financial interest.

\section{Biographies}

Valérie PICHON received her Ph.D. in 1995 with Marie-Claire Hennion in the Department of Analytical Chemistry at ESPCI Paris. She is full professor at Sorbonne University (Paris) since 2010 and leads the Department of Analytical, Bioanalytical Sciences and Miniaturization of the Institute of Chemistry Biology and Innovation located at the ESPCI Paris, PSL University. Her major research interests include the synthesis and the characterization of stationary phases based on antibodies or aptamers and molecularly imprinted polymers to selectively extract target compounds present at the trace level in complex samples. She also works on the miniaturization of these sorbents to couple them on-line with nanoLC-MS or to develop lab-on-chip systems. She was rewarded in 2001 with the Analytical Chemistry Department of the French Society of Chemistry Prize and nominated in 2016 in " The Power list " by The Analytical Scientist, which recognizes the 50 most influential women in analytical chemistry at the international level.

Nathalie Delaunay holds a Ph.D. degree in analytical chemistry from the University of Pierre et Marie Curie Paris and a Master degree from ESPCI Paris. She is a CNRS researcher at the LSABM (ESPCI Paris). She focuses her research on the development of analytical methods for trace analysis by liquid chromatography and capillary electrophoresis in complex samples. She also works on electrokinetic or selective preconcentration techniques (immunosorbents, ion-imprinted polymers). The targeted compounds can be lanthanide or polyoxometallic ions, PAHs, explosives or glycoproteins. She is the author of about 60 publications. She is currently President of Club lle-de-France of AfSep (Francophonic Association of Separation Sciences).

Audrey Combes received her Ph.D of University Pierre and Marie Curie (Paris, France) in Biochemistry, with Jean-Michel Camadro in the Department of Mitochondria, Metals and Oxidative stress at Jacques Monod Institute. Her research interest involve sample treatment based on molecular recognition and LC/MS analyses for developing targeted, and quantitative approach, and untargeted approach (metabolomic) for small molecules in different type of environmental or biological samples. 
(1) Hennion, M.-C.; Pichon, V. Immuno-Based Sample Preparation for Trace Analysis. J. Chromatogr. A 2003, 1000 (1), 29-52.

(2) Şenyuva, H. Z.; Gilbert, J. Immunoaffinity Column Clean-up Techniques in Food Analysis: A Review. J. Chromatogr. B 2010, 878 (2), 115-132. https://doi.org/10.1016/j.jchromb.2009.05.042.

(3) Tsikas, D. Quantitative Analysis of Biomarkers, Drugs and Toxins in Biological Samples by Immunoaffinity Chromatography Coupled to Mass Spectrometry or Tandem Mass Spectrometry: A Focused Review of Recent Applications. J. Chromatogr. B 2010, 878 (2), 133-148. https://doi.org/10.1016/j.jchromb.2009.11.008.

(4) Pichon, V.; Combès, A.; Delaunay, N. Immunosorbents in Microextraction. TrAC Trends Anal. Chem. 2019, 113, 246-255. https://doi.org/10.1016/j.trac.2019.02.016.

(5) Pichon, V.; Brothier, F.; Combès, A. Aptamer-Based-Sorbents for Sample Treatment-a Review. Anal. Bioanal. Chem. 2015, 407 (3), 681-698.

(6) Du, F.; Guo, L.; Qin, Q.; Zheng, X.; Ruan, G.; Li, J.; Li, G. Recent Advances in AptamerFunctionalized Materials in Sample Preparation. TrAC Trends Anal. Chem. 2015, 67, 134-146. https://doi.org/10.1016/j.trac.2015.01.007.

(7) Acquah, C.; Danquah, M. K.; Yon, J. L. S.; Sidhu, A.; Ongkudon, C. M. A Review on Immobilised Aptamers for High Throughput Biomolecular Detection and Screening. Anal. Chim. Acta 2015, 888, 10-18. https://doi.org/10.1016/j.aca.2015.05.050.

(8) Pichon, V. 6 - Aptamer-Based and Immunosorbents. In Solid-Phase Extraction; Poole, C. F., Ed.; Handbooks in Separation Science; Elsevier, 2020; pp 151-183. https://doi.org/10.1016/B978-0-12-816906-3.00006-6.

(9) Ahmad, O. S.; Bedwell, T. S.; Esen, C.; Garcia-Cruz, A.; Piletsky, S. A. Molecularly Imprinted Polymers in Electrochemical and Optical Sensors. Trends Biotechnol. 2019, 37 (3), 294-309. https://doi.org/10.1016/j.tibtech.2018.08.009.

(10) BelBruno, J. J. Molecularly Imprinted Polymers. Chem. Rev. 2019, 119 (1), 94-119. https://doi.org/10.1021/acs.chemrev.8b00171.

(11) Yin, Y.; Dong, Z.; Luo, Q.; Liu, J. Biomimetic Catalysts Designed on Macromolecular Scaffolds. Top. Issue Polym. Biomater. 2012, 37 (11), 1476-1509. https://doi.org/10.1016/j.progpolymsci.2012.04.001.

(12) Tuwahatu, C. A.; Yeung, C. C.; Lam, Y. W.; Roy, V. A. L. The Molecularly Imprinted Polymer Essentials: Curation of Anticancer, Ophthalmic, and Projected Gene Therapy Drug Delivery Systems. J. Controlled Release 2018, 287, 24-34. https://doi.org/10.1016/j.jconrel.2018.08.023.

(13) Rutkowska, M.; Płotka-Wasylka, J.; Morrison, C.; Wieczorek, P. P.; Namieśnik, J.; Marć, M. Application of Molecularly Imprinted Polymers in Analytical Chiral Separations and Analysis. TrAC Trends Anal. Chem. 2018, 102, 91-102. https://doi.org/10.1016/j.trac.2018.01.011.

(14) Zheng, C.; Huang, Y.-P.; Liu, Z.-S. Synthesis and Theoretical Study of Molecularly Imprinted Monoliths for HPLC. Anal. Bioanal. Chem. 2013, 405 (7), 2147-2161. https://doi.org/10.1007/s00216-012-6639-6.

(15) Cheong, W. J.; Ali, F.; Choi, J. H.; Lee, J. O.; Yune Sung, K. Recent Applications of Molecular Imprinted Polymers for Enantio-Selective Recognition. Talanta 2013, 106, 45-59. https://doi.org/10.1016/j.talanta.2012.11.049.

(16) Wei, Z.-H.; Mu, L.-N.; Huang, Y.-P.; Liu, Z.-S. Imprinted Monoliths: Recent Significant Progress in Analysis Field. TrAC Trends Anal. Chem. 2017, 86, 84-92. https://doi.org/10.1016/j.trac.2016.10.009.

(17) lacob, B.-C.; Bodoki, E.; Oprean, R. Recent Advances in Capillary Electrochromatography Using Molecularly Imprinted Polymers. Electrophoresis 2014, 35 (19), 2722-2732. https://doi.org/10.1002/elps.201400253. 
(18) Mu, L.-N.; Wei, Z.-H.; Liu, Z.-S. Current Trends in the Development of Molecularly Imprinted Polymers in CEC: CE and CEC. Electrophoresis 2015, 36 (5), 764-772.

https://doi.org/10.1002/elps.201400389.

(19) Sellergren, B. Direct Drug Determination by Selective Sample Enrichment on an Imprinted Polymer. Anal. Chem. 1994, 66 (9), 1578-1582. https://doi.org/10.1021/ac00081a036.

(20) Pichon, V. Selective Sample Treatment Using Molecularly Imprinted Polymers. J. Chromatogr. A 2007, 1152 (1), 41-53.

(21) Tan, J.; Jiang, Z.-T.; Li, R.; Yan, X.-P. Molecularly-Imprinted Monoliths for Sample Treatment and Separation. New Mater. Anal. Chem. 2012, 39, 207-217. https://doi.org/10.1016/j.trac.2012.05.009.

(22) Farooq, S.; Nie, J.; Cheng, Y.; Yan, Z.; Li, J.; Bacha, S. A. S.; Mushtaq, A.; Zhang, H. Molecularly Imprinted Polymers' Application in Pesticide Residue Detection. Analyst 2018, 143 (17), 3971-3989. https://doi.org/10.1039/C8AN00907D.

(23) Ndunda, E. N.; Mizaikoff, B. Molecularly Imprinted Polymers for the Analysis and Removal of Polychlorinated Aromatic Compounds in the Environment: A Review. Analyst 2016, 141 (11), 3141-3156. https://doi.org/10.1039/C6AN00293E.

(24) Boysen, R. I. Advances in the Development of Molecularly Imprinted Polymers for the Separation and Analysis of Proteins with Liquid Chromatography. J. Sep. Sci. 2019, 42 (1), 5171. https://doi.org/10.1002/jssc.201800945.

(25) Xing, R.; Wen, Y.; He, H.; Guo, Z.; Liu, Z. Recent Progress in the Combination of Molecularly Imprinted Polymer-Based Affinity Extraction and Mass Spectrometry for Targeted Proteomic Analysis. TrAC Trends Anal. Chem. 2019, 110, 417-428. https://doi.org/10.1016/j.trac.2018.11.033.

(26) Ansari, S.; Masoum, S. Molecularly Imprinted Polymers for Capturing and Sensing Proteins: Current Progress and Future Implications. TrAC Trends Anal. Chem. 2019, 114, 29-47. https://doi.org/10.1016/j.trac.2019.02.008.

(27) Jia, M.; Zhang, Z.; Li, J.; Ma, X.; Chen, L.; Yang, X. Molecular Imprinting Technology for Microorganism Analysis. TrAC Trends Anal. Chem. 2018, 106, 190-201. https://doi.org/10.1016/j.trac.2018.07.011.

(28) Zhu, G.; Cheng, G.; Wang, P.; Li, W.; Wang, Y.; Fan, J. Water Compatible Imprinted Polymer Prepared in Water for Selective Solid Phase Extraction and Determination of Ciprofloxacin in Real Samples. Talanta 2019, 200, 307-315. https://doi.org/10.1016/j.talanta.2019.03.070.

(29) Almeida, J. M. S.; Toloza, C. A. T.; Machado, B. S.; da Silva, A. R.; Aucelio, R. Q. Determination of Gentamicin Sulfate by Batch-Injection Amperometry after Solid-Phase Extraction Using a Kanamycin-Template Imprinted Polymer. Microchem. J. 2019, 145, 187-195. https://doi.org/10.1016/j.microc.2018.10.041.

(30) Boulanouar, S.; Combès, A.; Mezzache, S.; Pichon, V. Synthesis and Application of Molecularly Imprinted Silica for the Selective Extraction of Some Polar Organophosphorus Pesticides from Almond Oil. Anal. Chim. Acta 2018, 1018, 35-44. https://doi.org/10.1016/j.aca.2018.02.069.

(31) Du, L.; Cheng, Z.; Zhu, P.; Chen, Q.; Wu, Y.; Tan, K. Preparation of Mesoporous Silica Nanoparticles Molecularly Imprinted Polymer for Efficient Separation and Enrichment of Perfluorooctane Sulfonate. J. Sep. Sci. 2018, 41 (23), 4363-4369. https://doi.org/10.1002/jssc.201800587.

(32) Gast, M.; Sobek, H.; Mizaikoff, B. Selective Virus Capture via Hexon Imprinting. Mater. Sci. Eng. C 2019, 99, 1099-1104. https://doi.org/10.1016/j.msec.2019.02.037.

(33) Guo, L.; Ma, X.; Xie, X.; Huang, R.; Zhang, M.; Li, J.; Zeng, G.; Fan, Y. Preparation of DualDummy-Template Molecularly Imprinted Polymers Coated Magnetic Graphene Oxide for Separation and Enrichment of Phthalate Esters in Water. Chem. Eng. J. 2019, 361, 245-255. https://doi.org/10.1016/j.cej.2018.12.076.

(34) Hu, L.; Zhou, T.; Luo, D.; Feng, J.; Tao, Y.; Zhou, Y.; Mei, S. Bioaccumulation of Tetrabromobisphenol A in a Laboratory-Based Fish-Water System Based on Selective 
Magnetic Molecularly Imprinted Solid-Phase Extraction. Sci. Total Environ. 2019, 650, $1356-$ 1362. https://doi.org/10.1016/j.scitotenv.2018.09.002.

(35) Shi, W.; Zhang, S.-Q.; Li, K.-B.; Jia, W.-P.; Han, D.-M. Integration of Mixed-Mode Chromatography and Molecular Imprinting Technology for Double Recognition and Selective Separation of Proteins. Sep. Purif. Technol. 2018, 202, 165-173.

https://doi.org/10.1016/j.seppur.2018.03.057.

(36) Wang, F.; Li, X.; Li, J.; Zhu, C.; Liu, M.; Wu, Z.; Liu, L.; Tan, X.; Lei, F. Preparation and Application of a Molecular Capture for Safety Detection of Cosmetics Based on Surface Imprinting and Multi-Walled Carbon Nanotubes. J. Colloid Interface Sci. 2018, 527, 124-131. https://doi.org/10.1016/j.jcis.2018.05.030.

(37) Wang, Y.; Tian, M.; Yu, K.; Li, L.; Zhang, Z.; Li, L. A Versatile Strategy to Fabricate Magnetic Dummy Molecularly Imprinted Mesoporous Silica Particles for Specific Magnetic Separation of Bisphenol A. New J. Chem. 2019, 43 (8), 3400-3408. https://doi.org/10.1039/C8NJ06027D.

(38) Ding, H.; Wang, R.; Wang, X.; Ji, W. Molecularly Imprinted Covalent Organic Polymers for the Selective Extraction of Benzoxazole Fluorescent Whitening Agents from Food Samples. J. Sep. Sci. 2018, 41 (16), 3294-3301. https://doi.org/10.1002/jssc.201800540.

(39) Wang, M.; Chang, X.; Wu, X.; Yan, H.; Qiao, F. Water-Compatible Dummy Molecularly Imprinted Resin Prepared in Aqueous Solution for Green Miniaturized Solid-Phase Extraction of Plant Growth Regulators. J. Chromatogr. A 2016, 1458, 9-17. https://doi.org/10.1016/j.chroma.2016.06.047.

(40) Alatawi, R. A. S.; Monier, M.; Elsayed, N. H. Chiral Separation of ( \pm )-Methamphetamine Racemate Using Molecularly Imprinted Sulfonic Acid Functionalized Resin. J. Colloid Interface Sci. 2018, 531, 654-663. https://doi.org/10.1016/j.jcis.2018.07.070.

(41) Fan, H.; Wang, J.; Meng, Q.; Jin, Z. Monodisperse Hollow-Shell Structured Molecularly Imprinted Polymers for Photocontrolled Extraction $\alpha$-Cyclodextrin from Complex Samples. Food Chem. 2019, 281, 1-7. https://doi.org/10.1016/j.foodchem.2018.12.084.

(42) Zhang, Y.-Z.; Zhang, J.; Tan, L.; Xia, Z.; Wang, C.-Z.; Zhou, L.-D.; Zhang, Q.; Yuan, C.-S. Preparation and Evaluation of Temperature and Magnetic Dual-Responsive Molecularly Imprinted Polymers for the Specific Enrichment of Formononetin. J. Sep. Sci. 2018, 41 (15), 3060-3068. https://doi.org/10.1002/jssc.201800275.

(43) Zhang, R.; Zhang, T.; Lv, Y.; Qin, P.; Li, H.; Li, J.; Tan, T. Selective Binding of Heparin Oligosaccharides in a Magnetic Thermoresponsive Molecularly Imprinted Polymer. Talanta 2019, 201, 441-449. https://doi.org/10.1016/j.talanta.2019.04.050.

(44) Zhou, J.; Wang, Y.; Ma, Y.; Zhang, B.; Zhang, Q. Surface Molecularly Imprinted ThermoSensitive Polymers Based on Light-Weight Hollow Magnetic Microspheres for Specific Recognition of BSA. Appl. Surf. Sci. 2019, 486, 265-273. https://doi.org/10.1016/j.apsusc.2019.04.159.

(45) Tang, W.; Row, K. H. Novel Controllable Hydrophilic Thermo-Responsive Molecularly Imprinted Resin Adsorbent Prepared in Water for Selective Recognition of Alkaloids by Thermal-Assisted Dispersive Solid Phase Extraction. J. Pharm. Biomed. Anal. 2018, 160, 386396. https://doi.org/10.1016/j.jpba.2018.08.019.

(46) Wang, X.; Pei, Y.; Hou, Y.; Pei, Z. Fabrication of Core-Shell Magnetic Molecularly Imprinted Nanospheres towards Hypericin via Click Polymerization. Polymers 2019, 11 (2). https://doi.org/10.3390/polym11020313.

(47) Li, L.; Yu, K.; Tian, M.; Wang, Y.; Zhang, Z.; Jiang, G.; Li, L. Rapid Extraction of Trace Bisphenol A in Real Water Samples Using Hollow Mesoporous Silica Surface Dummy Molecularly Imprinted Polymers. Anal. Methods 2018, 10 (32), 3926-3932. https://doi.org/10.1039/C8AY01530A.

(48) Bai, X.; Liu, S.; Liu, J.; Ma, Y.; Zhang, W.; Pan, J. Specific Uptake Luteolin by Boronate AffinityBased Single-Hole Hollow Imprinted Polymers Sealed in Dialysis Bags. Chem. Eng. J. 2018, 353, 911-919. https://doi.org/10.1016/j.cej.2018.07.190. 
(49) Yao, J.; Ma, Y.; Liu, J.; Liu, S.; Pan, J. Janus-like Boronate Affinity Magnetic Molecularly Imprinted Nanobottles for Specific Adsorption and Fast Separation of Luteolin. Chem. Eng. J. 2019, 356, 436-444. https://doi.org/10.1016/j.cej.2018.09.003.

(50) Li, D.; Yuan, Q.; Yang, W.; Yang, M.; Li, S.; Tu, T. Efficient Vitamin B12-Imprinted Boronate Affinity Magnetic Nanoparticles for the Specific Capture of Vitamin B12. Anal. Biochem. 2018, 561-562, 18-26. https://doi.org/10.1016/j.ab.2018.09.009.

(51) Huang, W.; Hou, X.; Tong, Y.; Tian, M. Determination of Sialic Acid in Serum Samples by Dispersive Solid-Phase Extraction Based on Boronate-Affinity Magnetic Hollow Molecularly Imprinted Polymer Sorbent. RSC Adv. 2019, 9 (10), 5394-5401. https://doi.org/10.1039/C9RA00511K.

(52) Yu, X.; Liu, H.; Diao, J.; Sun, Y.; Wang, Y. Magnetic Molecularly Imprinted Polymer Nanoparticles for Separating Aromatic Amines from Azo Dyes - Synthesis, Characterization and Application. Sep. Purif. Technol. 2018, 204, 213-219. https://doi.org/10.1016/j.seppur.2018.04.081.

(53) Tonucci, M. C.; Fidélis, A. L. S.; Baeta, B. E. L.; Tarley, C. R. T.; de Aquino, S. F. Influence of Synthesis Conditions on the Production of Molecularly Imprinted Polymers for the Selective Recovery of Isovaleric Acid from Anaerobic Effluents. Polym. Int. 2019, 68 (3), 428-438. https://doi.org/10.1002/pi.5726.

(54) Tan, S.; Yu, H.; He, Y.; Wang, M.; Liu, G.; Hong, S.; Yan, F.; Wang, Y.; Wang, M.; Li, T.; et al. A Dummy Molecularly Imprinted Solid-Phase Extraction Coupled with Liquid ChromatographyTandem Mass Spectrometry for Selective Determination of Four Pyridine Carboxylic Acid Herbicides in Milk. J. Chromatogr. B 2019, 1108, 65-72. https://doi.org/10.1016/j.jchromb.2019.01.008.

(55) Wang, M.; Liang, S.; Bai, L.; Qiao, F.; Yan, H. Green Protocol for the Preparation of Hydrophilic Molecularly Imprinted Resin in Water for the Efficient Selective Extraction and Determination of Plant Hormones from Bean Sprouts. Anal. Chim. Acta 2019, 1064, 4755. https://doi.org/10.1016/j.aca.2019.03.025.

(56) Wan, Y.; Wang, M.; Fu, Q.; Wang, L.; Wang, D.; Zhang, K.; Xia, Z.; Gao, D. Novel Dual Functional Monomers Based Molecularly Imprinted Polymers for Selective Extraction of Myricetin from Herbal Medicines. J. Chromatogr. B 2018, 1097-1098, 1-9. https://doi.org/10.1016/j.jchromb.2018.08.033.

(57) Gomes, C. P.; Dias, R. C. S.; Costa, M. R. P. F. N. Preparation of Molecularly Imprinted Adsorbents with Improved Retention Capability of Polyphenols and Their Application in Continuous Separation Processes. Chromatographia 2019, 82 (6), 893-916. https://doi.org/10.1007/s10337-019-03728-7.

(58) Panjan, P.; Monasterio, R. P.; Carrasco-Pancorbo, A.; Fernandez-Gutierrez, A.; Sesay, A. M.; Fernandez-Sanchez, J. F. Development of a Folic Acid Molecularly Imprinted Polymer and Its Evaluation as a Sorbent for Dispersive Solid-Phase Extraction by Liquid Chromatography Coupled to Mass Spectrometry. J. Chromatogr. A 2018, 1576, 26-33. https://doi.org/10.1016/j.chroma.2018.09.037.

(59) Li, Z.; Lei, C.; Wang, N.; Jiang, X.; Zeng, Y.; Fu, Z.; Zou, L.; He, L.; Liu, S.; Ao, X.; et al. Preparation of Magnetic Molecularly Imprinted Polymers with Double Functional Monomers for the Extraction and Detection of Chloramphenicol in Food. J. Chromatogr. B 2018, 11001101, 113-121. https://doi.org/10.1016/j.jchromb.2018.09.032.

(60) Song, X.; Zhou, T.; Zhang, J.; Su, Y.; Zhou, H.; He, L. Preparation and Application of Molecularly Imprinted Monolithic Extraction Column for the Selective Microextraction of Multiple Macrolide Antibiotics from Animal Muscles. Polymers 2019, 11, 1109.

(61) Hudson, A. D.; Sola, R.; Ueta, J. T.; Battell, W.; Jamieson, O.; Dunbar, T.; Macia, B.; Peeters, M. Synthesis of Optimized Molecularly Imprinted Polymers for the Isolation and Detection of Antidepressants via HPLC Dagger. Biomimetics 2019, 4 (1). https://doi.org/10.3390/biomimetics4010018. 
(62) Wang, R.; Cui, Y.; Hu, F.; Liu, W.; Du, Q.; Zhang, Y.; Zha, J.; Huang, T.; Fizir, M.; He, H. Selective Recognition and Enrichment of Carbamazepine in Biological Samples by Magnetic Imprinted Polymer Based on Reversible Addition-Fragmentation Chain Transfer Polymerization. J. Chromatogr. A 2019, 1591, 62-70. https://doi.org/10.1016/j.chroma.2019.01.057.

(63) Phungpanya, C.; Chaipuang, A.; Machan, T.; Watla-iad, K.; Thongpoon, C.; Suwantong, O. Synthesis of Prednisolone Molecularly Imprinted Polymer Nanoparticles by Precipitation Polymerization. Polym. Adv. Technol. 2018, 29 (12), 3075-3084. https://doi.org/10.1002/pat.4428.

(64) Yuan, Y.; Yang, C.; Lv, T.; Qiao, F.; Zhou, Y.; Yan, H. Green Synthesis of Hydrophilic ProteinImprinted Resin with Specific Recognition of Bovine Serum Albumin in Aqueous Matrix. Anal. Chim. Acta 2018, 1033, 213-220. https://doi.org/10.1016/j.aca.2018.06.009.

(65) Lu, W.; Liu, J.; Li, J.; Wang, X.; Lv, M.; Cui, R.; Chen, L. Dual-Template Molecularly Imprinted Polymers for Dispersive Solid-Phase Extraction of Fluoroquinolones in Water Samples Coupled with High Performance Liquid Chromatography. Analyst 2019, 144 (4), 1292-1302. https://doi.org/10.1039/C8AN02133C.

(66) Li, D.; Tu, T.; Wu, X. Efficient Preparation of Template Immobilization-Based Boronate Affinity Surface-Imprinted Silica Nanoparticles Using Poly(4-Aminobenzyl Alcohol) as an Imprinting Coating for Glycoprotein Recognition. Anal. Methods 2018, 10 (36), 4419-4429. https://doi.org/10.1039/C8AY00632F.

(67) Marć, M.; Panuszko, A.; Namieśnik, J.; Wieczorek, P. P. Preparation and Characterization of Dummy-Template Molecularly Imprinted Polymers as Potential Sorbents for the Recognition of Selected Polybrominated Diphenyl Ethers. Anal. Chim. Acta 2018, 1030, 77-95. https://doi.org/10.1016/j.aca.2018.05.022.

(68) Lu, C.; Tang, Z.; Gao, X.; Ma, X.; Liu, C. Computer-Aided Design of Magnetic Dummy Molecularly Imprinted Polymers for Solid-Phase Extraction of Ten Phthalates from Food Prior to Their Determination by GC-MS/MS. Microchim. Acta 2018, 185 (8), 373. https://doi.org/10.1007/s00604-018-2892-5.

(69) Attallah, O. A.; Al-Ghobashy, M. A.; Ayoub, A. T.; Nebsen, M. Magnetic Molecularly Imprinted Polymer Nanoparticles for Simultaneous Extraction and Determination of 6-Mercaptopurine and Its Active Metabolite Thioguanine in Human Plasma. J. Chromatogr. A 2018, 1561, $28-$ 38. https://doi.org/10.1016/j.chroma.2018.05.038.

(70) Xie, J.; Xiong, J.; Ding, L.-S.; Chen, L.; Zhou, H.; Liu, L.; Zhang, Z.-F.; Hu, X.-M.; Luo, P.; Qing, L.S. A Efficient Method to Identify Cardioprotective Components of Astragali Radix Using a Combination of Molecularly Imprinted Polymers-Based Knockout Extract and Activity Evaluation. J. Chromatogr. A 2018, 1576, 10-18. https://doi.org/10.1016/j.chroma.2018.09.027.

(71) Wang, P.; Zhu, H.; Liu, J.; Ma, Y.; Yao, J.; Dai, X.; Pan, J. Double Affinity Integrated MIPs Nanoparticles for Specific Separation of Glycoproteins: A Combination of Synergistic Multiple Bindings and Imprinting Effect. Chem. Eng. J. 2019, 358, 143-152.

https://doi.org/10.1016/j.cej.2018.09.168.

(72) Shao, H.; Zhou, H.; Zhang, T.; Zhao, X.; Jiang, Z.; Wang, Q. Preparation of Molecularly Imprinted Hybrid Monoliths for the Selective Detection of Fluoroquinolones in Infant Formula Powders. J. Chromatogr. A 2019, 1588, 33-40. https://doi.org/10.1016/j.chroma.2018.12.038.

(73) Zhu, G.; Cheng, G.; Wang, L.; Yu, W.; Wang, P.; Fan, J. A New lonic Liquid Surface-Imprinted Polymer for Selective Solid-Phase-Extraction and Determination of Sulfonamides in Environmental Samples. J. Sep. Sci. 2019, 42 (3), 725-735. https://doi.org/10.1002/jssc.201800759.

(74) Sorribes-Soriano, A.; Esteve-Turrillas, F. A.; Armenta, S.; Amorós, P.; Herrero-Martínez, J. M. Amphetamine-Type Stimulants Analysis in Oral Fluid Based on Molecularly Imprinting Extraction. Anal. Chim. Acta 2019, 1052, 73-83. https://doi.org/10.1016/j.aca.2018.11.046. 
(75) Murakami, T.; Iwamuro, Y.; Ishimaru, R.; Chinaka, S.; Hasegawa, H. Molecularly Imprinted Polymer Solid-Phase Extraction of Synthetic Cathinones from Urine and Whole Blood Samples. J. Sep. Sci. 2018, 41 (24), 4506-4514. https://doi.org/10.1002/jssc.201800874.

(76) Abrão, L. C. de C.; Figueiredo, E. C. A New Restricted Access Molecularly Imprinted Fiber for Direct Solid Phase Microextraction of Benzodiazepines from Plasma Samples. Analyst 2019, 144 (14), 4320-4330. https://doi.org/10.1039/C9AN00444K.

(77) Tang, J.; Wang, J.; Shi, S.; Hu, S.; Yuan, L. Determination of Beta-Agonist Residues in AnimalDerived Food by a Liquid Chromatography-Tandem Mass Spectrometric Method Combined with Molecularly Imprinted Stir Bar Sorptive Extraction. J. Anal. METHODS Chem. 2018. https://doi.org/10.1155/2018/9053561.

(78) Hashemi, S. H.; Kaykhaii, M.; Tabehzar, F. Spectrophotometric Determination of Four Naphthalene Sulfonates in Sea Water after Their Molecularly Imprinted Stir Bar Sorptive Extraction. J. Chil. Chem. Soc. 2018, 63, 4057-4063.

(79) Liu, Y.; Liu, Y.; Liu, Z.; Du, F.; Qin, G.; Li, G.; Hu, X.; Xu, Z.; Cai, Z. Supramolecularly Imprinted Polymeric Solid Phase Microextraction Coatings for Synergetic Recognition Nitrophenols and Bisphenol A. J. Hazard. Mater. 2019, 368, 358-364.

https://doi.org/10.1016/j.jhazmat.2019.01.039.

(80) Chen, L.; Wu, J.; Huang, X. Multiple Monolithic Fibers Modified with a Molecularly Imprinted Polymer for Solid Phase Microextraction of Sulfonylurea Herbicides Based on Boron-Nitrogen Interaction. Microchim. Acta 2019, 186 (7), 470. https://doi.org/10.1007/s00604-019-36107.

(81) Sun, X.; Wang, M.; Yang, L.; Wen, H.; Wang, L.; Li, T.; Tang, C.; Yang, J. Preparation and Evaluation of Dummy-Template Molecularly Imprinted Polymer as a Potential Sorbent for Solid Phase Extraction of Imidazole Fungicides from River Water. J. Chromatogr. A 2019, 1586, 1-8. https://doi.org/10.1016/j.chroma.2018.11.077.

(82) Tang, J.; Wang, J.; Yuan, L.; Xiao, Y.; wang, X.; Yang, Z. Trace Analysis of Estrogens in Milk Samples by Molecularly Imprinted Solid Phase Extraction with Genistein as a Dummy Template Molecule and High-Performance Liquid Chromatography-Tandem Mass Spectrometry. Steroids 2019, 145, 23-31. https://doi.org/10.1016/j.steroids.2019.02.010.

(83) Yagishita, M.; Kubo, T.; Nakano, T.; Shiraishi, F.; Tanigawa, T.; Naito, T.; Sano, T.; Nakayama, S. F.; Nakajima, D.; Otsuka, K. Efficient Extraction of Estrogen Receptor-Active Compounds from Environmental Surface Water via a Receptor-Mimic Adsorbent, a Hydrophilic PEGBased Molecularly Imprinted Polymer. Chemosphere 2019, 217, 204-212. https://doi.org/10.1016/j.chemosphere.2018.10.194.

(84) Wang, X.; Huang, P.; Ma, X.; Du, X.; Lu, X. Enhanced In-out-Tube Solid-Phase Microextraction by Molecularly Imprinted Polymers-Coated Capillary Followed by HPLC for Endocrine Disrupting Chemicals Analysis. Talanta 2019, 194, 7-13. https://doi.org/10.1016/j.talanta.2018.10.027.

(85) Mirzajani, R.; Kardani, F.; Ramezani, Z. A Nanocomposite Consisting of Graphene Oxide, Zeolite Imidazolate Framework 8, and a Molecularly Imprinted Polymer for (Multiple) Fiber Solid Phase Microextraction of Sterol and Steroid Hormones Prior to Their Quantitation by HPLC. Microchim. Acta 2019, 186 (3), 129. https://doi.org/10.1007/s00604-018-3217-4.

(86) Wang, C.; Ding, C.; Wu, Q.; Xiong, X. Molecularly Imprinted Polymers with Dual Template and Bifunctional Monomers for Selective and Simultaneous Solid-Phase Extraction and Gas Chromatographic Determination of Four Plant Growth Regulators in Plant-Derived Tissues and Foods. Food Anal. Methods 2019, 12 (5), 1160-1169. https://doi.org/10.1007/s12161019-01455-1.

(87) Wang, S.; She, Y.; Hong, S.; Du, X.; Yan, M.; Wang, Y.; Qi, Y.; Wang, M.; Jiang, W.; Wang, J. Dual-Template Imprinted Polymers for Class-Selective Solid-Phase Extraction of Seventeen Triazine Herbicides and Metabolites in Agro-Products. J. Hazard. Mater. 2019, 367, 686-693. https://doi.org/10.1016/j.jhazmat.2018.12.089. 
(88) Ma, W.; Row, K. H. Simultaneous Determination of Levofloxacin and Ciprofloxacin in Human Urine by lonic-Liquid-Based, Dual-Template Molecularly Imprinted Coated Graphene Oxide Monolithic Solid-Phase Extraction. J. Sep. Sci. 2019, 42 (3), 642-649.

https://doi.org/10.1002/jssc.201800939.

(89) Liu, X.; Wu, F.; Au, C.; Tao, Q.; Pi, M.; Zhang, W. Synthesis of Molecularly Imprinted Polymer by Suspension Polymerization for Selective Extraction of P-Hydroxybenzoic Acid from Water. J. Appl. Polym. Sci. 2019, 136 (3), 46984. https://doi.org/10.1002/app.46984.

(90) Li, Z.; Qian, Z.; Hu, S.; Gong, T.; Xian, Q. Molecularly Imprinted Solid Phase Extraction Coupled with Gas Chromatography-Mass Spectrometry for Determination of N-Nitrosodiphenylamine in Water Samples. Chemosphere 2018, 212, 872-880. https://doi.org/10.1016/j.chemosphere.2018.08.159.

(91) Kadhirvel, P.; Combès, A.; Bordron, L.; Pichon, V. Development and Application of WaterCompatible Molecularly Imprinted Polymers for the Selective Extraction of Carbamazepine from Environmental Waters. Anal. Bioanal. Chem. 2019. https://doi.org/10.1007/s00216019-01586-8.

(92) Sun, X.; Wang, M.; Peng, J.; Yang, L.; Wang, X.; Wang, F.; Zhang, X.; Wu, Q.; Chen, R.; Chen, J. Dummy Molecularly Imprinted Solid Phase Extraction of Climbazole from Environmental Water Samples. Talanta 2019, 196, 47-53. https://doi.org/10.1016/j.talanta.2018.12.017.

(93) Combes, A.; Kadhirvel, P.; Bordron, L.; Pichon, V. Synthesis and Characterization of Molecularly Imprinted Polymers for the Selective Extraction of Carbamazepine and Analogs from Human Urine Samples. Chromatographia 2019, 82 (1), 287-295. https://doi.org/10.1007/s10337-018-3680-4.

(94) Tian, X.; She, C.; Qi, Z.; Xu, X. Magnetic-Graphene Oxide Based Molecularly Imprinted Polymers for Selective Extraction of Microsystin-LR Prior to the Determination by HPLC. Microchem. J. 2019, 146, 1126-1133. https://doi.org/10.1016/j.microc.2019.02.033.

(95) Vaneckova, T.; Vanickova, L.; Tvrdonova, M.; Pomorski, A.; Krężel, A.; Vaculovic, T.; Kanicky, V.; Vaculovicova, M.; Adam, V. Molecularly Imprinted Polymers Coupled to Mass Spectrometric Detection for Metallothionein Sensing. Talanta 2019, 198, 224-229. https://doi.org/10.1016/j.talanta.2019.01.089.

(96) Bagheri, A. R.; Arabi, M.; Ghaedi, M.; Ostovan, A.; Wang, X.; Li, J.; Chen, L. Dummy Molecularly Imprinted Polymers Based on a Green Synthesis Strategy for Magnetic SolidPhase Extraction of Acrylamide in Food Samples. Talanta 2019, 195, 390-400. https://doi.org/10.1016/j.talanta.2018.11.065.

(97) Gholami, H.; Ghaedi, M.; Arabi, M.; Ostovan, A.; Bagheri, A. R.; Mohamedian, H. Application of Molecularly Imprinted Biomembrane for Advancement of Matrix Solid-Phase Dispersion for Clean Enrichment of Parabens from Powder Sunscreen Samples: Optimization of Chromatographic Conditions and Green Approach. ACS Omega 2019, 4 (2), 3839-3849. https://doi.org/10.1021/acsomega.8b02963.

(98) Arabzadeh, N.; Akbarzadeh, R.; Mohammadi, A.; Darwish, M. Green Synthesis and Application of Nanomagnetic Molecularly Imprinted Polymerfor Fast Solid-Phase Extraction of Brilliant Blue FCF from Real Samples. J. Polym. Res. 2018, 26 (1), 8. https://doi.org/10.1007/s10965-018-1665-5.

(99) Díaz-Liñán, M. C.; López-Lorente, A. I.; Cárdenas, S.; Lucena, R. Molecularly Imprinted PaperBased Analytical Device Obtained by a Polymerization-Free Synthesis. Sens. Actuators $B$ Chem. 2019, 287, 138-146. https://doi.org/10.1016/j.snb.2019.02.048.

(100) Ardekani, R.; Borhani, S.; Rezaei, B. Simple Preparation and Characterization of Molecularly Imprinted Nylon 6 Nanofibers for the Extraction of Bisphenol A from Wastewater. J. Appl. Polym. Sci. 2019, 136 (9), 47112. https://doi.org/10.1002/app.47112.

(101) Ayadi, C.; Anene, A.; Kalfat, R.; Chevalier, Y.; Hbaieb, S. Molecularly Imprinted Polyaniline on Silica Support for the Selective Adsorption of Benzophenone-4 from Aqueous Media. Colloids Surf. Physicochem. Eng. Asp. 2019, 567, 32-42.

https://doi.org/10.1016/j.colsurfa.2019.01.042. 
(102) Zhu, H.; Yao, H.; Xia, K.; Liu, J.; Yin, X.; Zhang, W.; Pan, J. Magnetic Nanoparticles Combining Teamed Boronate Affinity and Surface Imprinting for Efficient Selective Recognition of Glycoproteins under Physiological PH. Chem. Eng. J. 2018, 346, 317-328. https://doi.org/10.1016/j.cej.2018.03.170.

(103) Sun, Y. K.; Sun, G.-Y.; Jia, M.; Yang, J.; Liu, Z.-S.; Huang, Y.-P.; Aisa, H. A. Cost-Effective Imprinting to Minimize Consumption of Template in Room-Temperature lonic Liquid for Fast Purification of Chlorogenic Acid from the Extract of E. Ulmoides Leaves. Anal. Bioanal. Chem. 2019, 411 (6), 1261-1271. https://doi.org/10.1007/s00216-018-1559-8.

(104) Yang, F.-F.; Li, Z.-X.; Xu, Y.-J.; Huang, Y.-P.; Liu, Z.-S. Enhanced Molecular Recognition for Imprinted Monolithic Column Containing Polyhedral Oligomeric Silsesquioxanes by Dendritic Effect of Mesoporous Molecular Sieve Scaffolds. Anal. Bioanal. Chem. 2018, 410 (21), 51835193. https://doi.org/10.1007/s00216-018-1166-8.

(105) Zhang, Y.; Cao, H.; Huang, Q.; Liu, X.; Zhang, H. Isolation of Transferrin by Imprinted Nanoparticles with Magnetic Deep Eutectic Solvents as Monomer. Anal. Bioanal. Chem. 2018, 410 (24), 6237-6245. https://doi.org/10.1007/s00216-018-1232-2.

(106) Xu, W.; Wang, Y.; Wei, X.; Chen, J.; Xu, P.; Ni, R.; Meng, J.; Zhou, Y. Fabrication of Magnetic Polymers Based on Deep Eutectic Solvent for Separation of Bovine Hemoglobin via Molecular Imprinting Technology. Anal. Chim. Acta 2019, 1048, 1-11. https://doi.org/10.1016/j.aca.2018.10.044.

(107) Li, X.; Dai, Y.; Row, K. H. Preparation of Two-Dimensional Magnetic Molecularly Imprinted Polymers Based on Boron Nitride and a Deep Eutectic Solvent for the Selective Recognition of Flavonoids. Analyst 2019, 144 (5), 1777-1788. https://doi.org/10.1039/C8AN02258E.

(108) Ma, W.; Dai, Y.; Row, K. H. Molecular Imprinted Polymers Based on Magnetic Chitosan with Different Deep Eutectic Solvent Monomers for the Selective Separation of Catechins in Black Tea. ELECTROPHORESIS 2018, 39 (15), 2039-2046. https://doi.org/10.1002/elps.201800034.

(109) Li, G.; Row, K. H. Selective Extraction of 3,4-Dihydroxybenzoic Acid in Ilex Chinensis Sims by Meticulous Mini-Solid-Phase Microextraction Using Ternary Deep Eutectic Solvent-Based Molecularly Imprinted Polymers. Anal. Bioanal. Chem. 2018, 410 (30), 7849-7858. https://doi.org/10.1007/s00216-018-1406-y.

(110) Dolak, I.; Keçili, R.; Onat, R.; Ziyadanoğulları, B.; Ersöz, A.; Say, R. Molecularly Imprinted Affinity Cryogels for the Selective Recognition of Myoglobin in Blood Serum. Collect. Sel. Contrib. TURCMOS 2017 2018, 1174, 171-176. https://doi.org/10.1016/j.molstruc.2018.03.126.

(111) Sun, X.-Y.; Ma, R.-T.; Chen, J.; Shi, Y.-P. Magnetic Boronate Modified Molecularly Imprinted Polymers on Magnetite Microspheres Modified with Porous TiO2 (Fe3O4@pTiO2@MIP) with Enhanced Adsorption Capacity for Glycoproteins and with Wide Operational PH Range. Microchim. Acta 2018, 185 (12), 565. https://doi.org/10.1007/s00604-018-3092-z.

(112) Bie, Z.; Xing, R.; He, X.; Ma, Y.; Chen, Y.; Liu, Z. Precision Imprinting of Glycopeptides for Facile Preparation of Glycan-Specific Artificial Antibodies. Anal. Chem. 2018, 90 (16), 98459852. https://doi.org/10.1021/acs.analchem.8b01903.

(113) Zhang, Z.; Wang, H.; Wang, H.; Wu, C.; Li, M.; Li, L. Fabrication and Evaluation of Molecularly Imprinted Magnetic Nanoparticles for Selective Recognition and Magnetic Separation of Lysozyme in Human Urine. Analyst 2018, 143 (23), 5849-5856. https://doi.org/10.1039/C8AN01746H.

(114) Xie, X.; Hu, Q.; Ke, R.; Zhen, X.; Bu, Y.; Wang, S. Facile Preparation of Photonic and Magnetic Dual Responsive Protein Imprinted Nanomaterial for Specific Recognition of Bovine Hemoglobin. Chem. Eng. J. 2019, 371, 130-137. https://doi.org/10.1016/j.cej.2019.04.019.

(115) He, P.; Zhu, H.; Ma, Y.; Liu, N.; Niu, X.; Wei, M.; Pan, J. Rational Design and Fabrication of Surface Molecularly Imprinted Polymers Based on Multi-Boronic Acid Sites for Selective Capture Glycoproteins. Chem. Eng. J. 2019, 367, 55-63. https://doi.org/10.1016/j.cej.2019.02.140. 
(116) Zhang, W.; Zhang, T.; Chen, Y. Simultaneous Quantification of Cyt c Interactions with HSP27 and $\mathrm{Bcl}-\mathrm{XL}$ Using Molecularly Imprinted Polymers (MIPs) Coupled with Liquid Chromatography-Tandem Mass Spectrometry (LC-MS/MS)-Based Targeted Proteomics. J. Proteomics 2019, 192, 188-195. https://doi.org/10.1016/j.jprot.2018.09.001.

(117) Xu, S.; Tan, J.; Chen, X.; Chen, X.; Liang, Y. Preparation of Synthetic Amanitin Epitope Imprinted Polymers via Thiol-Ene Click Reaction for Recognition and Extraction $\alpha$ - and $\beta$ Amanitins from Mushrooms. Chromatographia 2019, 82 (9), 1355-1363. https://doi.org/10.1007/s10337-019-03751-8.

(118) Qin, Y.-P.; Wang, H.-Y.; He, X.-W.; Li, W.-Y.; Zhang, Y.-K. Metal Chelation Dual-Template Epitope Imprinting Polymer via Distillation-Precipitation Polymerization for Recognition of Porcine Serum Albumin. Talanta 2018, 185, 620-627. https://doi.org/10.1016/j.talanta.2018.03.082.

(119) Gómez-Arribas, L. N.; Urraca, J. L.; Benito-Peña, E.; Moreno-Bondi, M. C. Tag-Specific Affinity Purification of Recombinant Proteins by Using Molecularly Imprinted Polymers. Anal. Chem. 2019, 91 (6), 4100-4106. https://doi.org/10.1021/acs.analchem.8b05731.

(120) Turiel, E.; Martín-Esteban, A. Molecularly Imprinted Polymers-Based Microextraction Techniques. TrAC Trends Anal. Chem. 2019, 118, 574-586.

https://doi.org/10.1016/j.trac.2019.06.016.

(121) Mansour, M. S. M.; Abdel-Shafy, H. I.; Mehaya, F. M. S. Valorization of Food Solid Waste by Recovery of Polyphenols Using Hybrid Molecular Imprinted Membrane. J. Environ. Chem. Eng. 2018, 6 (4), 4160-4170. https://doi.org/10.1016/j.jece.2018.06.019.

(122) Abbasi, S.; Haeri, S. A.; Sajjadifar, S. Bio-Dispersive Liquid Liquid Microextraction Based on Nano Rhamnolipid Aggregates Combined with Molecularly Imprinted-Solid Phase Extraction for Selective Determination of Paracetamol in Human Urine Samples Followed by HPLC. Microchem. J. 2019, 146, 106-114. https://doi.org/10.1016/j.microc.2018.12.065.

(123) Zhao, X.; Wang, J.; Wang, J.; Wang, S. Development of Water-Compatible Molecularly Imprinted Solid-Phase Extraction Coupled with High Performance Liquid ChromatographyTandem Mass Spectrometry for the Detection of Six Sulfonamides in Animal-Derived Foods. J. Chromatogr. A 2018, 1574, 9-17. https://doi.org/10.1016/j.chroma.2018.08.044.

(124) Liang, W.; Hu, H.; Zhong, W.; Zhang, M.; Ma, Y.; Guo, P.; Xin, M.; Yu, M.; Lin, H. Functionalization of Molecularly Imprinted Polymer Microspheres for the Highly Selective Removal of Contaminants from Aqueous Solutions and the Analysis of Food-Grade Fish Samples. POLYMERS 2018, 10 (10). https://doi.org/10.3390/polym10101130.

(125) Vicario, A.; Solari, M.; Felici, E.; Aragón, L.; Bertolino, F.; Gomez, M. R. Molecular Imprinting on Surface of Silica Particles for the Selective Extraction of Benzylparaben in Flow System Applied to Cosmetics and Water Samples. Microchem. J. 2018, 142, 329-334. https://doi.org/10.1016/j.microc.2018.06.031.

(126) Madhumanchi, S.; Jadda, R.; Suedee, R. Efficient Adsorptive Extraction Materials by Surface Protein-Imprinted Polymer over Silica Gel for Selective Recognition/Separation of Human Serum Albumin from Urine. J. Appl. Polym. Sci. 2019, 136 (1). https://doi.org/10.1002/app.46894.

(127) Rui, C.; He, J.; Li, Y.; Liang, Y.; You, L.; He, L.; Li, K.; Zhang, S. Selective Extraction and Enrichment of Aflatoxins from Food Samples by Mesoporous Silica FDU-12 Supported Aflatoxins Imprinted Polymers Based on Surface Molecularly Imprinting Technique. Talanta 2019, 201, 342-349. https://doi.org/10.1016/j.talanta.2019.04.019.

(128) Zhang, J.; Chen, Y.; Wu, W.; Wang, Z.; Chu, Y.; Chen, X. Hollow Porous Dummy Molecularly Imprinted Polymer as a Sorbent of Solid-Phase Extraction Combined with Accelerated Solvent Extraction for Determination of Eight Bisphenols in Plastic Products. Microchem. J. 2019, 145, 1176-1184. https://doi.org/10.1016/j.microc.2018.12.031.

(129) Xie, L.; Zhou, L.; Li, L.; Xie, X.; Li, Y. Preparation and Adsorption Selectivity of Deltamethrin Molecularly Imprinted Polymers by Two-Step Seed Swelling Method. J. Appl. Polym. Sci. 2019, 136 (16), 47415. https://doi.org/10.1002/app.47415. 
(130) Negarian, M.; Mohammadinejad, A.; Mohajeri, S. A. Preparation, Evaluation and Application of Core-Shell Molecularly Imprinted Particles as the Sorbent in Solid-Phase Extraction and Analysis of Lincomycin Residue in Pasteurized Milk. Food Chem. 2019, 288, 29-38. https://doi.org/10.1016/j.foodchem.2019.02.087.

(131) Wang, C.; Cheng, L.; Zhang, L.; Zuo, Y. Graphene Oxide Based Molecularly Imprinted Polymers Modified with $\beta$-Cyclodextrin for Selective Extraction of Di(2-Ethylhexyl) Phthalate in Environmental Waters. J. Sep. Sci. 2019, 42 (6), 1248-1256. https://doi.org/10.1002/jssc.201801171.

(132) Zarejousheghani, M.; Schrader, S.; Möder, M.; Mayer, T.; Borsdorf, H. Negative Electrospray Ionization Ion Mobility Spectrometry Combined with Paper-Based Molecular Imprinted Polymer Disks: A Novel Approach for Rapid Target Screening of Trace Organic Compounds in Water Samples. Talanta 2018, 190, 47-54. https://doi.org/10.1016/j.talanta.2018.07.076.

(133) Liang, G.; Guo, X.; Tan, X.; Mai, S.; Chen, Z.; Zhai, H. Molecularly Imprinted Monolithic Column Based on Functionalized $\beta$-Cyclodextrin and Multi-Walled Carbon Nanotubes for Selective Recognition of Benzimidazole Residues in Citrus Samples. Microchem. J. 2019, 146, 1285-1294. https://doi.org/10.1016/j.microc.2019.02.064.

(134) Yeşilova, E.; Osman, B.; Kara, A.; Tümay Özer, E. Molecularly Imprinted Particle Embedded Composite Cryogel for Selective Tetracycline Adsorption. Sep. Purif. Technol. 2018, 200, 155163. https://doi.org/10.1016/j.seppur.2018.02.002.

(135) Bouvarel, T.; Delaunay, N.; Pichon, V. Selective Extraction of Cocaine from Biological Samples with a Miniaturized Monolithic Molecularly Imprinted Polymer and On-Line Analysis in NanoLiquid Chromatography. Anal. Chim. Acta 2019. https://doi.org/10.1016/j.aca.2019.10.046.

(136) Wu, Z.; He, D.; Cui, B.; Jin, Z. Ultrasensitive Detection of Microcystin-LR with Gold Immunochromatographic Assay Assisted by a Molecular Imprinting Technique. Food Chem. 2019, 283, 517-521. https://doi.org/10.1016/j.foodchem.2019.01.064.

(137) Aria, M. M.; Sorribes-Soriano, A.; Jafari, M. T.; Nourbakhsh, F.; Esteve-Turrillas, F. A.; Armenta, S.; Herrero-Martínez, J. M.; de la Guardia, M. Uptake and Translocation Monitoring of Imidacloprid to Chili and Tomato Plants by Molecularly Imprinting Extraction - Ion Mobility Spectrometry. Microchem. J. 2019, 144, 195-202.

https://doi.org/10.1016/j.microc.2018.09.007.

(138) Novosvětská, L.; Chocholouš, P.; Švec, F.; Sklenářová, H. Fully Automated Method Based on On-Line Molecularly Imprinted Polymer Solid-Phase Extraction for Determination of Lovastatin in Dietary Supplements Containing Red Yeast Rice. Anal. Bioanal. Chem. 2019, 411 (6), 1219-1228. https://doi.org/10.1007/s00216-018-1554-0.

(139) Yu, H.; He, Y.; She, Y.; Wang, M.; Yan, Z.; Ren, J. H.; Cao, Z.; Shao, Y.; Wang, S.; Abd El-Aty, A. $M$.; et al. Preparation of Molecularly Imprinted Polymers Coupled with High-Performance Liquid Chromatography for the Selective Extraction of Salidroside from Rhodiola Crenulata. J. Chromatogr. B 2019, 1118-1119, 180-186. https://doi.org/10.1016/j.jchromb.2019.04.004.

(140) Sorribes-Soriano, A.; Esteve-Turrillas, F. A.; Armenta, S.; de la Guardia, M.; Herrero-Martínez, J. M. Cocaine Abuse Determination by Ion Mobility Spectrometry Using Molecular Imprinting. J. Chromatogr. A 2017, 1481, 23-30. https://doi.org/10.1016/j.chroma.2016.12.041.

(141) Santos, M. G.; Tavares, I. M. C.; Barbosa, A. F.; Bettini, J.; Figueiredo, E. C. Analysis of Tricyclic Antidepressants in Human Plasma Using Online-Restricted Access Molecularly Imprinted Solid Phase Extraction Followed by Direct Mass Spectrometry Identification/Quantification. Talanta 2017, 163, 8-16. https://doi.org/10.1016/j.talanta.2016.10.047.

(142) Capriotti, A. L.; Cavaliere, C.; La Barbera, G.; Montone, C. M.; Piovesana, S.; Laganà, A. Recent Applications of Magnetic Solid-Phase Extraction for Sample Preparation. Chromatographia 2019, 82 (8), 1251-1274. https://doi.org/10.1007/s10337-019-03721-0.

(143) Cantarella, M.; Carroccio, S. C.; Dattilo, S.; Avolio, R.; Castaldo, R.; Puglisi, C.; Privitera, V. Molecularly Imprinted Polymer for Selective Adsorption of Diclofenac from Contaminated Water. Chem. Eng. J. 2019, 367, 180-188. https://doi.org/10.1016/j.cej.2019.02.146. 
(144) Garcia, R.; Carreiro, E. P.; Prates Ramalho, J. P.; Burke, A. J.; Lima, J. C.; Gomes da Silva, M. D. R.; Costa Freitas, A. M.; Cabrita, M. J. A Photoswitchable "Host-Guest" Approach for the Selective Enrichment of Dimethoate from Olive Oil. Anal. Chim. Acta 2018, 1035, 60-69. https://doi.org/10.1016/j.aca.2018.07.017.

(145) da Silva, R. C. S.; Santos, M. N.; Pires, B. C.; Dinali, L. A. F.; Suquila, F. A. C.; Tarley, C. R. T.; Borges, K. B. Assessment of Surfactants on Performance of Molecularly Imprinted Polymer toward Adsorption of Pharmaceutical. J. Environ. Chem. Eng. 2019, 7 (2), 103037. https://doi.org/10.1016/j.jece.2019.103037.

(146) Yu, X.; Zhang, Z.; Li, W.; Zhang, R.; Jiao, H.; Zhao, J.; Sun, A.; Shi, X.; Chen, J. Development and Application of the Dispersive Solid-Phase Extraction Method Based on Molecular Imprinted Polymers for Removal of Matrix Components of Bivalve Shellfish Extracts in the GC-MS/MS Analysis of Amide/Dinitroaniline/Substituted Urea Herbicides. Chromatographia 2019, 82 (6), 961-970. https://doi.org/10.1007/s10337-019-03729-6.

(147) Abidi, H.; Ghaedi, M.; Rafiei, A.; Jelowdar, A.; Arabi, M.; Ostovan, A.; Asfaram, A. A Molecularly Imprinted Polymer Coupled with High-Performance Liquid Chromatography-UV for the Determination of Albendazole in Plasma and Urine Samples: CCD-RSM Design. New J. Chem. 2018, 42 (19), 15937-15945. https://doi.org/10.1039/C8NJ02893A.

(148) Ghasempour, Z.; Alizadeh Khaled-Abad, M.; Vardast, M. R.; Rezazad Bari, M.; Moghaddas Kia, E. Fabrication of Betanin Imprinted Polymer for Rapid Detection of Red Beet Adulteration in Pomegranate Juice. Polym. Bull. 2019, 76 (4), 1793-1805. https://doi.org/10.1007/s00289018-2444-5.

(149) Liang, X.; Liu, F.; Wan, Y.; Yin, X.; Liu, W. Facile Synthesis of Molecularly Imprinted Polymers for Selective Extraction of Tyrosine Metabolites in Human Urine. J. Chromatogr. A 2019, 1587, 34-41. https://doi.org/10.1016/j.chroma.2018.12.014.

(150) Zhou, T.; Zhao, Q.; Zhao, L.; Liu, H.; Wang, B.; Huang, N.; Ding, J.; Ding, L.; Li, Y. Molecularly Imprinted Polymers Combined with Membrane-Protected Solid-Phase Extraction to Detect Triazines in Tea Samples. Anal. Bioanal. Chem. 2018, 410 (21), 5173-5181. https://doi.org/10.1007/s00216-018-1171-y.

(151) Wan, L.; Chen, Z.; Huang, C.; Shen, X. Core-Shell Molecularly Imprinted Particles. TrAC Trends Anal. Chem. 2017, 95, 110-121. https://doi.org/10.1016/j.trac.2017.08.010.

(152) Dinc, M.; Esen, C.; Mizaikoff, B. Recent Advances on Core-Shell Magnetic Molecularly Imprinted Polymers for Biomacromolecules. TrAC Trends Anal. Chem. 2019, 114, 202-217. https://doi.org/10.1016/j.trac.2019.03.008.

(153) Wang, P.; Liu, J.; Chen, X.; Ma, X.; Guo, D.; Li, Z.; Pan, J. Janus Silica Nanosheets-Based MMIPs Platform for Synergetic Selective Capture and Fast Separation of 2'-Deoxyadenosine: Two Different Components Segmented on the Surface of One Object. Chem. Eng. J. 2019, 369, 793-802. https://doi.org/10.1016/j.cej.2019.03.175.

(154) Zengin, A.; Badak, M. U.; Aktas, N. Selective Separation and Determination of Quercetin from Red Wine by Molecularly Imprinted Nanoparticles Coupled with HPLC and Ultraviolet Detection. J. Sep. Sci. 2018, 41 (17), 3459-3466. https://doi.org/10.1002/jssc.201800437.

(155) Li, W.; Chen, N.; Zhu, Y.; Shou, D.; Zhi, M.; Zeng, X. A Nanocomposite Consisting of an Amorphous Seed and a Molecularly Imprinted Covalent Organic Framework Shell for Extraction and HPLC Determination of Nonsteroidal Anti-Inflammatory Drugs. Microchim. Acta 2019, 186 (2), 76. https://doi.org/10.1007/s00604-018-3187-6.

(156) Rahmati, E.; Rafiee, Z. A Biocompatible High Surface Area ZnO-Based Molecularly Imprinted Polymer for the Determination of Meloxicam in Water Media and Plasma. New J. Chem. 2019, 43 (22), 8492-8501. https://doi.org/10.1039/C9NJ01386E.

(157) Zhao, X.; Duan, F.; Cui, P.; Yang, Y.; Liu, X.; Hou, X. A Molecularly-Imprinted Polymer Decorated on Graphene Oxide for the Selective Recognition of Quercetin. New Carbon Mater. 2018, 33 (6), 529-543. https://doi.org/10.1016/S1872-5805(18)60355-5.

(158) An, F.-Q.; Li, H.-F.; Guo, X.-D.; Hu, T.-P.; Gao, B.-J.; Gao, J.-F. Design of Novel “Imprinting Synchronized with Crosslinking" Surface Imprinted Technique and Its Application for 
Selectively Removing Phenols from Aqueous Solution. Eur. Polym. J. 2019, 112, 273-282. https://doi.org/10.1016/j.eurpolymj.2019.01.015.

(159) Hua, S.; Zhao, L.; Cao, L.; Wang, X.; Gao, J.; Xu, C. Fabrication and Evaluation of Hollow Surface Molecularly Imprinted Polymer for Rapid and Selective Adsorption of Dibenzothiophene. Chem. Eng. J. 2018, 345, 414-424. https://doi.org/10.1016/j.cej.2018.03.128.

(160) Yang, X.; Chen, J.; Liu, H.; Li, X.; Zhong, S. Molecularly Imprinted Polymers Based on Zeolite Imidazolate Framework-8 for Selective Removal of 2,4-Dichlorophenoxyacetic Acid. Colloids Surf. Physicochem. Eng. Asp. 2019, 570, 244-250. https://doi.org/10.1016/j.colsurfa.2019.03.038.

(161) Huang, S.; Xu, J.; Zheng, J.; Zhu, F.; Xie, L.; Ouyang, G. Synthesis and Application of Magnetic Molecularly Imprinted Polymers in Sample Preparation. Anal. Bioanal. Chem. 2018, 410 (17), 3991-4014. https://doi.org/10.1007/s00216-018-1013-y.

(162) Garcia, R.; Carreiro, E. P.; Prates Ramalho, J. P.; Mirão, J.; Burke, A. J.; Gomes da Silva, M. D. R.; Freitas, A. M. C.; Cabrita, M. J. A Magnetic Controllable Tool for the Selective Enrichment of Dimethoate from Olive Oil Samples: A Responsive Molecular Imprinting-Based Approach. Food Chem. 2018, 254, 309-316. https://doi.org/10.1016/j.foodchem.2018.02.003.

(163) Cheng, Y.; Nie, J.; Li, J.; Liu, H.; Yan, Z.; Kuang, L. Synthesis and Characterization of Core-Shell Magnetic Molecularly Imprinted Polymers for Selective Recognition and Determination of Quercetin in Apple Samples. Food Chem. 2019, 287, 100-106. https://doi.org/10.1016/j.foodchem.2019.02.069.

(164) Safdarian, M.; Ramezani, Z. Rapid Microwave-Assisted Distillation-Precipitation Polymerization for the Synthesis of Magnetic Molecular Imprinted Polymers Coupled to HPTLC Determination of Perphenazine in Human Urine. New J. Chem. 2019, 43 (1), 48-57. https://doi.org/10.1039/C8NJ05062G.

(165) Peyrovi, M.; Hadjmohammadi, M.; Saeidi, I. Synthesis of Magnetic Nanoparticle-Based Molecularly Imprinted Polymer as a Selective Sorbent for Efficient Extraction of Ezetimibe from Biological Samples. Biomed. Chromatogr. 2019, 33 (1, SI). https://doi.org/10.1002/bmc.4404.

(166) Yang, W.; Muhammad, T.; Yigaimu, A.; Muhammad, K.; Chen, L. Preparation of Stoichiometric Molecularly Imprinted Polymer Coatings on Magnetic Particles for the Selective Extraction of Auramine O from Water. J. Sep. Sci. 2018, 41 (22), 4185-4193. https://doi.org/10.1002/jssc.201800797.

(167) Lu, Y. C.; Guo, M. H.; Mao, J. H.; Xiong, X. H.; Liu, Y. J.; Li, Y. Preparation of Core-Shell Magnetic Molecularly Imprinted Polymer Nanoparticle for the Rapid and Selective Enrichment of Trace Diuron from Complicated Matrices. Ecotoxicol. Environ. Saf. 2019, 177, 66-76. https://doi.org/10.1016/j.ecoenv.2019.03.117.

(168) Chen, F.; Wang, J.; Lu, R.; Chen, H.; Xie, X. Fast and High-Efficiency Magnetic Surface Imprinting Based on Microwave-Accelerated Reversible Addition Fragmentation Chain Transfer Polymerization for the Selective Extraction of Estrogen Residues in Milk. J. Chromatogr. A 2018, 1562, 19-26. https://doi.org/10.1016/j.chroma.2018.05.047.

(169) Asfaram, A.; Arabi, M.; Ostovan, A.; Sadeghi, H.; Ghaedi, M. Simple and Selective Detection of Quercetin in Extracts of Plants and Food Samples by Dispersive-Micro-Solid Phase Extraction Based on Core-Shell Magnetic Molecularly Imprinted Polymers. New J. Chem. 2018, 42 (19), 16144-16153. https://doi.org/10.1039/C8NJ03349H.

(170) Zhao, Q.-Y.; Zhao, H.-T.; Yang, X.; Zhang, H.; Dong, A.-J.; Wang, J.; Li, B. Selective Recognition and Fast Enrichment of Anthocyanins by Dummy Molecularly Imprinted Magnetic Nanoparticles. J. Chromatogr. A 2018, 1572, 9-19. https://doi.org/10.1016/j.chroma.2018.08.029.

(171) Wang, H.; Yuan, L.; Zhu, H.; Jin, R.; Xing, J. Comparative Study of Capsaicin Molecularly Imprinted Polymers Prepared by Different Polymerization Methods. J. Polym. Sci. Part Polym. Chem. 2019, 57 (2), 157-164. https://doi.org/10.1002/pola.29281. 
(172) Zhong, M.; Wang, Y.-H.; Wang, L.; Long, R.-Q.; Chen, C.-L. Synthesis and Characterization of Magnetic Molecularly Imprinted Polymers for Enrichment of Sanguinarine from the Extraction Wastewater of M. Cordata. J. Ind. Eng. Chem. 2018, 66, 107-115. https://doi.org/10.1016/j.jiec.2018.05.019.

(173) Li, H.; Long, R.; Tong, C.; Li, T.; Liu, Y.; Shi, S. Shell Thickness Controlled Hydrophilic Magnetic Molecularly Imprinted Resins for High-Efficient Extraction of Benzoic Acids in Aqueous Samples. Talanta 2019, 194, 969-976. https://doi.org/10.1016/j.talanta.2018.10.099.

(174) Hu, C.; Yang, Z.; Yan, F.; Sun, B. Extraction of the Toluene Exposure Biomarkers Hippuric Acid and Methylhippuric Acid Using a Magnetic Molecularly Imprinted Polymer, and Their Quantitation by LC-MS/MS. Microchim. Acta 2019, 186 (3), 135. https://doi.org/10.1007/s00604-019-3239-6.

(175) Qin, D.; Wang, J.; Ge, C.; Lian, Z. Fast Extraction of Chloramphenicol from Marine Sediments by Using Magnetic Molecularly Imprinted Nanoparticles. Microchim. Acta 2019, 186 (7), 428. https://doi.org/10.1007/s00604-019-3548-9.

(176) Alvani-Alamdari, S.; Jouyban, A.; Khoubnasabjafari, M.; Nokhodchi, A.; Rahimpour, E. Efficiency Comparison of Nylon-6-Based Solid-Phase and Stir Bar Sorptive Extractors for Carbamazepine Extraction. Bioanalysis 2019, 11 (9), 899-911.

(177) Ma, X.; Lin, H.; He, Y.; She, Y.; Wang, M.; Abd El-Aty, A. M.; Afifi, N. A.; Han, J.; Zhou, X.; Wang, J.; et al. Magnetic Molecularly Imprinted Polymers Doped with Graphene Oxide for the Selective Recognition and Extraction of Four Flavonoids from Rhododendron Species. J. Chromatogr. A 2019, 1598, 39-48. https://doi.org/10.1016/j.chroma.2019.03.053.

(178) Ganjavi, F.; Ansari, M.; Kazemipour, M.; Zeidabadinejad, L. Computational Design, Synthesis and Utilization of a Magnetic Molecularly Imprinted Polymer on Graphene Oxide Nanosheets for Highly Selective Extraction and Determination of Buprenorphine in Biological Fluids and Tablets. Anal. Methods 2018, 10 (43), 5214-5226. https://doi.org/10.1039/C8AY01757C.

(179) Xie, X.; Ma, X.; Guo, L.; Fan, Y.; Zeng, G.; Zhang, M.; Li, J. Novel Magnetic Multi-Templates Molecularly Imprinted Polymer for Selective and Rapid Removal and Detection of Alkylphenols in Water. Chem. Eng. J. 2019, 357, 56-65. https://doi.org/10.1016/j.cej.2018.09.080.

(180) Zhao, X.; Chen, L.; Li, B. Magnetic Molecular Imprinting Polymers Based on ThreeDimensional (3D) Graphene-Carbon Nanotube Hybrid Composites for Analysis of Melamine in Milk Powder. Food Chem. 2018, 255, 226-234. https://doi.org/10.1016/j.foodchem.2018.02.078.

(181) Ge, Y.-H.; Shu, H.; Xu, X.-Y.; Guo, P.-Q.; Liu, R.-L.; Luo, Z.-M.; Chang, C.; Fu, Q. Combined Magnetic Porous Molecularly Imprinted Polymers and Deep Eutectic Solvents for Efficient and Selective Extraction of Aristolochic Acid I and II from Rat Urine. Mater. Sci. Eng. C 2019, 97, 650-657. https://doi.org/10.1016/j.msec.2018.12.057.

(182) Wu, C.; He, J.; Li, Y.; Chen, N.; Huang, Z.; You, L.; He, L.; Zhang, S. Solid-Phase Extraction of Aflatoxins Using a Nanosorbent Consisting of a Magnetized Nanoporous Carbon Core Coated with a Molecularly Imprinted Polymer. Microchim. Acta 2018, 185 (11), 515. https://doi.org/10.1007/s00604-018-3051-8.

(183) Wei, S.-L.; Liu, W.-T.; Huang, X.-C.; Ma, J.-K. Preparation and Application of a Magnetic Plasticizer as a Molecularly Imprinted Polymer Adsorbing Material for the Determination of Phthalic Acid Esters in Aqueous Samples. J. Sep. Sci. 2018, 41 (19), 3806-3814. https://doi.org/10.1002/jssc.201800535.

(184) Sorribes-Soriano, A.; Esteve-Turrillas, F. A.; Armenta, S.; Montoya, A.; Herrero-Martínez, J. M.; de la Guardia, M. Magnetic Molecularly Imprinted Polymers for the Selective Determination of Cocaine by Ion Mobility Spectrometry. J. Chromatogr. A 2018, 1545, 22-31. https://doi.org/10.1016/j.chroma.2018.02.055.

(185) Kumar, N.; Narayanan, N.; Gupta, S. Ultrasonication Assisted Extraction of Chlorpyrifos from Honey and Brinjal Using Magnetic Molecularly Imprinted Polymers Followed by GLC-ECD 
Analysis. React. Funct. Polym. 2019, 135, 103-112.

https://doi.org/10.1016/j.reactfunctpolym.2018.12.012.

(186) Benedetti, B.; Di Carro, M.; Magi, E. Multivariate Optimization of an Extraction Procedure Based on Magnetic Molecular Imprinted Polymer for the Determination of Polycyclic Aromatic Hydrocarbons in Sea Water. Microchem. J. 2019, 145, 1199-1206. https://doi.org/10.1016/j.microc.2018.12.048.

(187) Sorribes-Soriano, A.; Arráez-González, R.; Esteve-Turrillas, F. A.; Armenta, S.; HerreroMartínez, J. M. Development of a Molecularly Imprinted Monolithic Polymer Disk for Agitation-Extraction of Ecgonine Methyl Ester from Environmental Water. Talanta 2019, 199, 388-395. https://doi.org/10.1016/j.talanta.2019.02.077.

(188) Liang, Y.; Zhao, Q.; Liu, H.; Chen, X.; Zhang, D.; Lai, X.; Li, B.; Yang, X. Amido SurfaceFunctionalized Magnetic Molecularly Imprinted Polymers for the Efficient Extraction of Sibiskoside from Sibiraea Angustata. J. Chromatogr. B 2019, 1109, 90-98. https://doi.org/10.1016/j.jchromb.2019.01.009.

(189) Khezeli, T.; Daneshfar, A. Development of Dispersive Micro-Solid Phase Extraction Based on Micro and Nano Sorbents. TrAC Trends Anal. Chem. 2017, 89, 99-118.

https://doi.org/10.1016/j.trac.2017.01.004.

(190) Lashgari, M.; Yamini, Y. An Overview of the Most Common Lab-Made Coating Materials in Solid Phase Microextraction. Talanta 2019, 191, 283-306. https://doi.org/10.1016/j.talanta.2018.08.077.

(191) Sarafraz-Yazdi, A.; Razavi, N. Application of Molecularly-Imprinted Polymers in Solid-Phase Microextraction Techniques. TrAC Trends Anal. Chem. 2015, 73, 81-90. https://doi.org/10.1016/j.trac.2015.05.004.

(192) Wang, D.-D.; Gao, D.; Huang, Y.-K.; Xu, W.-J.; Xia, Z.-N. Preparation of Restricted Access Molecularly Imprinted Polymers Based Fiber for Selective Solid-Phase Microextraction of Hesperetin and Its Metabolites in Vivo. Talanta 2019, 202, 392-401. https://doi.org/10.1016/j.talanta.2019.05.016.

(193) Rahimi, M.; Bahar, S.; Heydari, R.; Amininasab, S. M. Determination of Quercetin Using a Molecularly Imprinted Polymer as Solid-Phase Microextraction Sorbent and HighPerformance Liquid Chromatography. Microchem. J. 2019, 148, 433-441. https://doi.org/10.1016/j.microc.2019.05.032.

(194) Mirzajani, R.; Ramezani, Z.; Kardani, F. Selective Determination of Thidiazuron Herbicide in Fruit and Vegetable Samples Using Molecularly Imprinted Polymer Fiber Solid Phase Microextraction with Ion Mobility Spectrometry Detection (MIPF-SPME-IMS). Microchem. J. 2017, 130, 93-101. https://doi.org/10.1016/j.microc.2016.08.009.

(195) David, F.; Ochiai, N.; Sandra, P. Two Decades of Stir Bar Sorptive Extraction: A Retrospective and Future Outlook. TrAC Trends Anal. Chem. 2019, 112, 102-111. https://doi.org/10.1016/j.trac.2018.12.006.

(196) Tang, T.; Wei, F.; Wang, X.; Ma, Y.; Song, Y.; Ma, Y.; Song, Q.; Xu, G.; Cen, Y.; Hu, Q. Determination of Semicarbazide in Fish by Molecularly Imprinted Stir Bar Sorptive Extraction Coupled with High Performance Liquid Chromatography. J. Chromatogr. B 2018, 1076, 8-14. https://doi.org/10.1016/j.jchromb.2018.01.003.

(197) Díaz-Álvarez, M.; Turiel, E.; Martín-Esteban, A. Molecularly Imprinted Polymer Monolith Containing Magnetic Nanoparticles for the Stir-Bar Sorptive Extraction of Thiabendazole and Carbendazim from Orange Samples. Anal. Chim. Acta 2019, 1045, 117-122. https://doi.org/10.1016/j.aca.2018.09.001.

(198) Rozaini, M. N. H.; Semail, N.; Saad, B.; Kamaruzaman, S.; Abdullah, W. N.; Rahim, N. A.; Miskam, M.; Loh, S. H.; Yahaya, N. Molecularly Imprinted Silica Gel Incorporated with Agarose Polymer Matrix as Mixed Matrix Membrane for Separation and Preconcentration of Sulfonamide Antibiotics in Water Samples. Talanta 2019, 199, 522-531. https://doi.org/10.1016/j.talanta.2019.02.096. 
(199) Larpant, N.; Suwanwong, Y.; Boonpangrak, S.; Laiwattanapaisal, W. Exploring Matrix Effects on Binding Properties and Characterization of Cotinine Molecularly Imprinted Polymer on Paper-Based Scaffold. POLYMERS 2019, 11, 570. https://doi.org/10.3390/polym11030570.

(200) Zengin, A.; Utku Badak, M.; Bilici, M.; Suludere, Z.; Aktas, N. Preparation of Molecularly Imprinted PDMS Elastomer for Selective Detection of Folic Acid in Orange Juice. Appl. Surf. Sci. 2019, 471, 168-175. https://doi.org/10.1016/j.apsusc.2018.12.008.

(201) Sanchez-Gonzalez, J.; Odoardi, S.; Maria Bermejo, A.; Bermejo-Barrera, P.; Saverio Romolo, F.; Moreda-Pineiro, A.; Strano-Rossi, S. HPLC-MS/MS Combined with Membrane-Protected Molecularly Imprinted Polymer Micro-Solid-Phase Extraction for Synthetic Cathinones Monitoring in Urine. DRUG Test. Anal. 2019, 11 (1), 33-44. https://doi.org/10.1002/dta.2448.

(202) Yao, R.; Yu, Z.; Wu, M.; Yu, H. Preparation and Evaluation of Molecularly Imprinted Membrane of Teicoplanin. Anal. Methods 2018, 10 (45), 5416-5422.

https://doi.org/10.1039/C8AY01623B. 